\title{
Comparative analysis of pyrimidine substituted aminoacyl-sulfamoyl nucleosides as potential inhibitors targeting class I aminoacyl-tRNA synthetases.
}

\author{
Manesh Nautiyal $^{1 \text { \#, Steff De Graef }}{ }^{2}$, Luping Pang ${ }^{1,2}$, Bharat Gadakh ${ }^{1}$, Sergei V. Strelkov ${ }^{2}$, Stephen \\ D. Weeks ${ }^{2, \infty}$ and Arthur Van Aerschot ${ }^{1, \infty, *}$ \\ ${ }^{1}$ Medicinal Chemistry, Rega Institute for Medical Research, KU Leuven, Herestraat 49 box 1041, B- \\ 3000 Leuven, Belgium \\ ${ }^{2}$ Laboratory for Biocrystallography, Department of Pharmaceutical and Pharmacological Sciences, \\ KU Leuven, Herestraat 49 box 822, B-3000 Leuven, Belgium \\ * To whom correspondence should be addressed. Tel: +32 163726 24; Fax: +32 163 37340; Email: \\ arthur.vanaerschot@kuleuven.be \\ \# These authors contributed equally to this work. \\ $\infty$ Both authors equally supervised and gave guidance to this work.
}

\begin{abstract}
Aminoacyl-tRNA synthetases (aaRSs) catalyze the ATP-dependent coupling of an amino acid to its cognate tRNA. Being vital for protein translation aaRSs are considered a promising target for the development of novel antimicrobial agents. 5'-O-( $N$-aminoacyl)-sulfamoyl adenosine (aaSA) is a non-hydrolysable analog of the aaRS reaction intermediate that has been shown to be a potent inhibitor of this enzyme family but is prone to chemical instability and enzymatic modification. In an attempt to improve the molecular properties of this scaffold we synthesized a series of base substituted aaSA analogues comprising cytosine, uracil and $N^{3}$-methyluracil targeting leucyl-, tyrosyl- and isoleucyl-tRNA synthetases. In in vitro assays seven out of the nine inhibitors demonstrated $\mathrm{K}_{\mathrm{i}}{ }^{\mathrm{app}}$ values in the low nanomolar range. To complement the biochemical studies, X-ray crystallographic structures of Neisseria gonorrhoeae leucyl-tRNA synthetase and Escherichia coli tyrosyl-tRNA synthetase in complex with the newly synthesized compounds were determined. These highlighted a subtle interplay between the base moiety and the target enzyme in defining relative inhibitory activity. Encouraged by this data we investigated if the pyrimidine congeners could escape a natural resistance mechanism, involving acetylation of the amine of the aminoacyl group by the bacterial $\mathrm{N}$ acetyltransferases RimL and YhhY. With RimL the pyrimidine congeners were less susceptible to inactivation compared to the equivalent aaSA, whereas with YhhY the converse was true. Combined the various insights resulting from this study will pave the way for the further rational design of aaRS inhibitors.
\end{abstract}




\section{Graphical abstract}

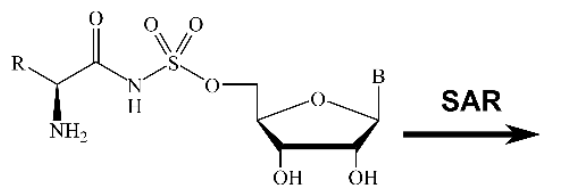

$\mathrm{R}=$ side chains of ile, leu and tyr $\mathrm{B}=$ cytosine, uracil, $N^{3}$-methyluracil

9 aaSA analogues synthesized

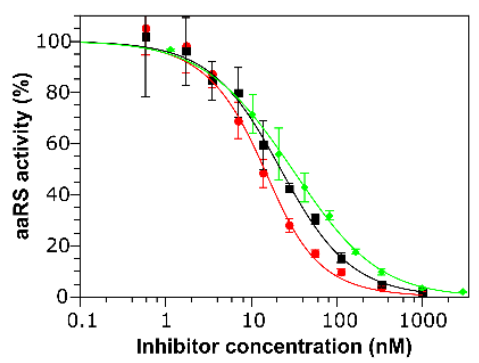

7 out 9 compounds have a $\mathrm{K}_{\mathrm{i}}^{\mathrm{app}}<150 \mathrm{nM}$

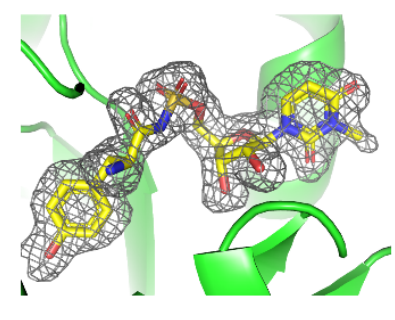

8 inhibitor-aaRS crystal structures were solved

\section{Keywords}

Aminoacyl-tRNA synthetase; bisubstrate competitive inhibitor; X-ray crystallography; Nacetyltransferase; structure-activity relationship

\section{Highlights}

1. Nine aminoacyl-sulfamoylated pyrimidine nucleosides were synthesized.

2. Several compounds displayed nanomolar activity in in vitro assays.

3. LeuRS and TyrRS ligand bound X-ray crystallographic structures determined.

4. Activity determined in cell extracts in the presence of $\mathrm{N}$-acetyl transferases.

5. N-acetyl transferase activity affected by both the base and the amino acid.

\section{INTRODUCTION}

Aminoacyl-tRNA synthetases (aaRSs) are a kingdom-wide family of enzymes that play a pivotal role in translating the genetic code. These proteins, all catalyze the two-step ligation of an amino acid to its cognate tRNA. In the first step, the amino acid is activated by nucleophilic attack of the $\alpha$ carboxylate on the $\alpha$-phosphate of adenosine triphosphate (ATP) generating aminoacyl-AMP (aaAMP, Fig. 1a) and pyrophosphate. The aa-AMP is then utilised in the second step whereby the aaRS catalyses the transesterification of the $2^{\prime}$ or $3^{\prime}$-hydroxyl of a tRNA terminal ribose, generating the charged aa-tRNA species[1]. In a typical bacterium there are 20 different aaRSs, one for each proteinogenic amino acid. Given their indispensable role in maintaining the fidelity of translation, aaRSs have been recognised as suitable targets for the development of new antimicrobials[2, 3]. Screening of both natural and synthetic molecules for aaRS inhibitors has yielded diverse sets of 
chemical structures[1, 4-7]. However, for various reasons only a limited number of compounds have reached the market. The best example is mupirocin (Fig. 1b), a competitive catalytic site inhibitor of isoleucyl-tRNA synthetase (ileRS), which is used as a topical treatment of impetigo resulting from Staphylococcus aureus (S. aureus) or Streptococcus pyogenes (S. pyogenes) infection.<smiles>[R]C(N)C(=O)OP(=O)([O-])OCC(O)OC(O)C(O)O</smiles>

a) Aminoacyl-AMP (aa-AMP)<smiles></smiles>

c) Aminoacyl-sulfamoyl adenosine (aaSA) b) Mupirocin (IleRS inhibitor)<smiles>CC(C)OC(=O)/C=C/CC1OCC(CC(=O)O)C(O)C1O</smiles>

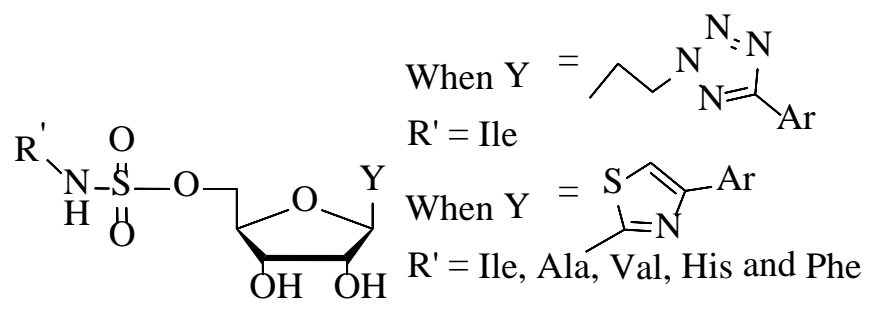

d) Cubist compounds

Fig. 1. The aaRS catalytic intermediate aa-AMP (a) and some well-known aaRS inhibitors, with the clinically approved mupirocin (b), general structure of aaSA analogues (c), and compounds developed at Cubist Pharmaceuticals (d). R in structures a and c corresponds to the side chain of a proteinogenic amino acid.

The largest group of aaRS inhibitors described so far are the non-hydrolysable analogues of aa-AMP, where the labile mixed anhydride linkage has been replaced with a hydrolytically stable linkage[8, 9]. Among them, the 5'-O-(N-L-aminoacyl)-sulfamoyl adenosine (aaSAs) analogues (Fig. 1c) have proven to be potent inhibitors in vitro[10]. Although having a strong affinity for the target aaRS, these compounds lack in vivo efficacy due to their high polarity, have limited species selectivity due to structural similarity with aa-AMP, and are prone to hydrolysis as a result of the formation of a cyclic adenosine derivative[11]. Furthermore, studies have shown that such compounds are prone to enzymatic degradation[12] or modification[13].

To address some of these issues, various efforts were made to modify the aaSA scaffold to obtain analogues with a better activity profile. Such approaches include the modification or shortening of the sulfur-based linker[14], substitution of the sugar ring[15] or the adenine base[16, 17]. In the latter case, Cubist Pharmaceuticals (now Merck) reported C-nucleosides where the adenine was replaced 
with either a functionalized thiazole[18] or ethyl-linked tetrazole derivatives[19] (Fig. 1d). The tetrazole analogues, designed to target isoleucyl-tRNA synthetase (ileRS), showed IC $_{50}$ values in the nanomolar range[20] with up to 2300 times higher selectivity towards the $S$. aureus and E. coli enzyme compared to the human orthologue[19]. Unfortunately, these compounds did not prove successful in vivo due to low cell permeability and strong binding to serum albumin[5, 19]. Therefore, mimicking the natural antibiotics albomycin and microcin $\mathrm{C}$, attempts were made to combine the tetrazole containing compounds with bacterial transport modules to improve uptake. While the compounds were correctly processed, they did not enter bacteria suggesting that the base in the natural compounds is necessary to traverse the bacterial cell wall[17].

In addition to in vivo efficacy, selectivity and hydrolysis issues, aaSA analogues are prone to undergo enzymatic degradation or inactivation by the action of peptidases[21], acetyltransferases[13, 22], and potentially by sulfatases[12]. In the case of acetyltransferases, members of the GCN5-related Nacetyltransferase (GNAT) family have been shown to catalyse the acetyl-coenzyme A (acetyl-coA) dependent modification of the $\alpha$-amine group of aaSAs preventing interaction of the compound with the target aaRS and therefore providing resistance to bacteria. Intriguingly, a recently discovered microcin $\mathrm{C}$ analog containing a modified cytidine base was shown to overcome GNAT mediated inactivation[23, 24].

Expanding on our previous study on ileRS inhibitors where adenosine was replaced with alternative natural and modified bases[16], we have investigated whether a pyrimidine substitution strategy could be extrapolated to other aaRSs. In particular, we have focused on ileRS, leucyl-tRNA synthetase (leuRS) and tyrosyl-tRNA synthetase (tyrRS). All three enzymes belong to the class I aaRS family, a subset with ten members sharing a catalytic domain based on a Rossmann fold[4]. We synthesized nine compounds [5-7(a-c)] substituting adenine for cytosine (C), uracil (U), or $N^{3}$-methyluracil (3meU). The synthesized congeners were evaluated for their ability to inhibit the corresponding aaRS in in vitro assays with both the purified enzyme and S30 E. coli extract. In the latter case the ability of the compounds to escape NAT catalysed inactivation was evaluated. To complement the biochemical analyses, high-resolution X-ray crystallographic structures were solved of the respective compounds bound to Neisseria gonorrhoeae (N. gonorrhoeae) leuRS and E. coli tyrRS permitting the development of a structure-activity relationship model.

\section{Results}

\section{Synthesis of pyrimidine aaSA analogues}


Synthesis of the desired compounds is straightforward and shown in Scheme 1, starting with persilylation of cytidine (1a) and uridine (1b)[16]. To obtain the $N^{3}$-methyluridine analog (2c), persilylated uridine (2a) was treated for $20 \mathrm{~h}$ with $\mathrm{MeI}$ in the presence of $\mathrm{K}_{2} \mathrm{CO}_{3}$ using DMF: acetone (1:1) as the solvent[25]. Selective desilylation at the 5'-O position was accomplished using TFA: water: THF (4:1:1) to afford 3a-c[26] and reaction with in situ generated sulfamoyl chloride lead to the formation of 5'-O-sulfamoylated analogues 4a-c. The 5'-O-sulfamoyl derivatives of uridine (4b) and $N^{3}$-methyluridine (4c) were condensed with the $N$-hydroxysuccinimide ester of appropriately protected amino acids in the presence of DBU. Acidolysis of intermediates was performed using TFA: $\mathrm{H}_{2} \mathrm{O}(5: 2)$ to remove Boc and TBDMS protecting groups, which was followed by hydrogenolysis for the tyrosine derivatives, leading to the desired 5'-O-(N-L-aminoacyl)sulfamoylated cytidines (aaSC, 5a-6a), uridines (aaSU, 5b-7b), and $N^{3}$-methyluridines (aaS3meU, 5c-7c). Only 7a proved cumbersome with reduction of the cytosine base upon hydrogenolysis. Hence, in this case the sidechain unprotected $\mathrm{N}$-hydroxysuccinimide ester of Boc-Tyr-OH was used for coupling to 5'-Osulfamoyl cytidine in the presence of DBU.

In the remainder of the manuscript, we will designate both the synthesized compounds and the aaSA analogues using a natural abbreviation, consisting of a letter (L, I or Y) indicating the amino acid, followed by the letter S for sulfamoyl, and finally abbreviated designation of the base (A, U, C or 3meU). This way, compound $\mathbf{5 a}$ becomes ISC etc.

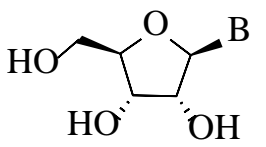

1a, $\mathrm{B}=$ Cytosine 1b, B= Uracil
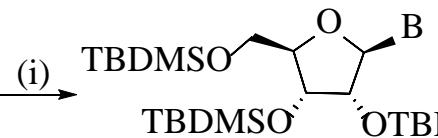

2a, $\mathrm{B}=$ Cytosine

$\mathbf{2 b}, \mathbf{B}=$ Uracil 2c, B= $N^{3}$-Me-Uracil (ii)

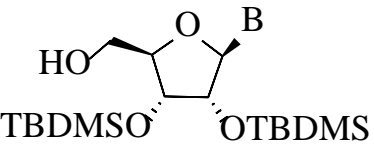

3a, $\mathrm{B}=$ Cytosine

$3 \mathbf{b}, \mathrm{B}=$ Uracil 3c, $\mathrm{B}=N^{3}$-Me-Uracil (iv)<smiles>[R]C(N)C(=O)NS(=O)(=O)OC[C@H]1O[C@H](I)[C@H](O)[C@H]1O</smiles>
(v), (vi), (vii)<smiles>[B]C1CC(O[R16](C)(C)C)C(COS(N)(=O)=O)O1</smiles>
5(a-c)-7(a-c) 4(a-c)

5a-c : $\mathrm{R}=\mathrm{CH}\left(\mathrm{CH}_{3}\right) \mathrm{CH}_{2} \mathrm{CH}_{3}:$, 6a-c $: \mathrm{R}=\mathrm{CH}_{2} \mathrm{CH}\left(\mathrm{CH}_{3}\right)_{2} ; \mathbf{7 a - c}: \mathrm{R}=\mathrm{CH}_{2} \mathrm{C}_{6} \mathrm{H}_{4}-\mathrm{p}-\mathrm{OH}$, for 4-7, a: B = Cytosine, b: B = Uracil c: B $=N^{3}$-Me-Uracil.

Scheme 1. Synthesis of 5'-O-(N-L-aminoacyl)-sulfamoyl nucleosides 5(a-c), 6(a-c) \& 7(a-c). 
Reagents and conditions: (i) TBDMSCl, imidazole, dry DMF, $50{ }^{\circ} \mathrm{C}, 20$ h; 82-89\% (ii) TFA: water: THF (4:1:1), $0{ }^{\circ} \mathrm{C}, 6$ h; 60-84\% (iii) MeI, $\mathrm{K}_{2} \mathrm{CO}_{3}$, DMF: acetone (1:1), Reflux, $50{ }^{\circ} \mathrm{C}, 20$ h, 81\%; (iv) $\mathrm{ClSO}_{2} \mathrm{NCO}$, formic acid, DMA, 66-72\%; (v) Boc-aa-( OBn)-Osu (or Boc-Tyr-Osu for 7a), DBU, DMF, 6-8 h; (vi) TFA: water (5:2), rt, 6 h; (vii) Pd/C, methanol, $\mathrm{H}_{2}$ atm. rt, overnight. Cumulative yields from steps v-vii were: 5c-74\%, 6a-58\%, 6b-82\%, 6c-65\%, 7a-30\%, 7b-62\%, 7c-60\%.

\section{In vitro assays with purified aaRSs}

The inhibitory activity of the synthesized derivatives was tested by performing an in vitro aminoacylation reaction and measuring the transfer of radiolabelled amino acid to tRNA. Reactions were carried out with a total tRNA pool and the appropriate purified enzyme from $E$. coli. In view of the strong inhibitory activity of the compounds under evaluation, dose-response data were fitted using the Greco-Hakala equation[27] (Fig. 2) and data were compared to the respective aaSA analogues (Table 1). While being weaker inhibitors than the aaSA analogues, all three uridine derivatives ISU, LSU and YSU (5b-7b) showed $K_{i}^{\text {app }}$ values in the nanomolar range against the respective enzymes (Table 1). $N^{3}$-methylation of this base (5c-7c) resulted in slightly weaker inhibition of tyrRS and leuRS, but led to an almost 20-fold reduction in activity of ileS3meU compared to ileSU, when evaluated against ileRS. The cytidine analogues (5a-7a) proved slightly more potent against leuRS and ileRS compared to the uridine congeners (5b-7b), with $\mathrm{K}_{\mathrm{i}}^{\text {app }}$ values of $10 \mathrm{nM}$ and $17 \mathrm{nM}$ for LSC and ISC, respectively. Remarkably, the inhibitory activity of YSC was strongly reduced resulting in a $\mathrm{K}_{\mathrm{i}}^{\text {app }}$ of around 1.5 micromolar.
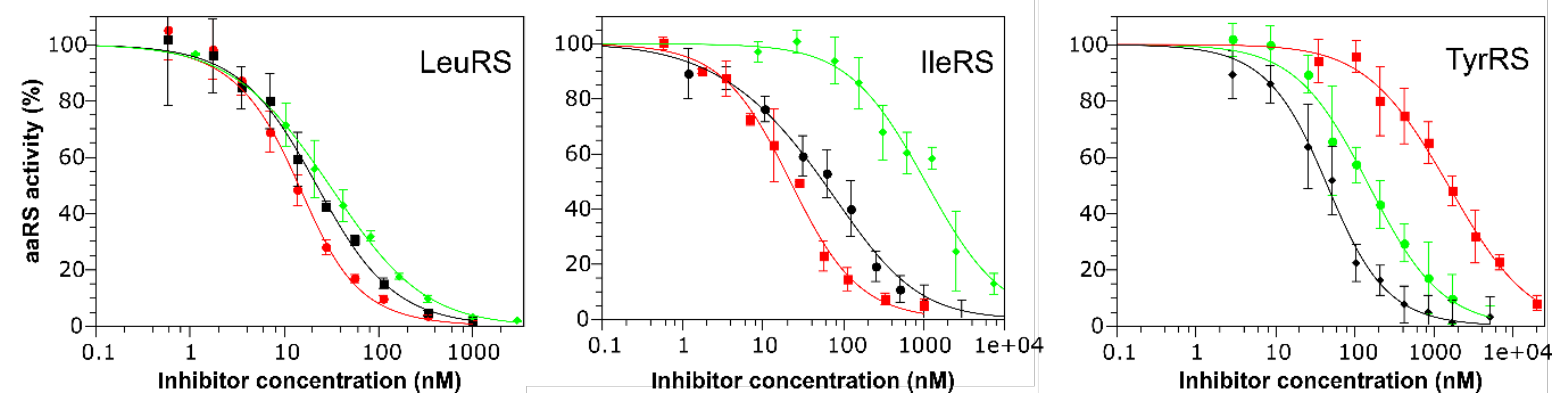

Fig. 2. Dose-response curves of leuRS, ileRS, and tyrRS from E. coli in the presence of serial dilutions of the pyrimidine analogues. The reactions contained $2.5 \mathrm{nM}$ leuRS, $10 \mathrm{nM}$ ileRS and $0.5 \mathrm{nM}$ tyrRS. Values were normalised to the control reaction containing no inhibitor. Points were fitted with the Greco-Hakala equation. All reactions were performed in triplicate, the average value and standard error are shown; red, green and black curves indicate cytidine, $N^{3}$-methyluridine and uridine derivatives respectively. 
Table 1. Enzyme inhibition values of the studied sulfonamides.

\begin{tabular}{ccccc}
\hline aaRS & $\mathrm{A}^{\mathrm{a}}$ & $\mathrm{U}$ & $\mathrm{C}$ & $3 \mathrm{meU}$ \\
\hline lleRS $^{\mathrm{b}}$ & $1.9 \pm 4.0$ & $55.0 \pm 7.6$ & $17.2 \pm 1.5$ & $1039 \pm 122$ \\
LeuRS $^{\mathrm{b}}$ & $0.14 \pm 0.1$ & $20.8 \pm 1.1$ & $9.8 \pm 0.4$ & $29.5 \pm 1.8$ \\
TyrRS $^{\mathrm{b}}$ & $2.9 \pm 1.2$ & $43.4 \pm 3.4$ & $1484 \pm 112$ & $149 \pm 12.0$
\end{tabular}

$\mathrm{K}_{\mathrm{i}}^{\text {app }}$ values of the aminoacylated sulfonamide nucleosides for the respective enzymes are given in $\mathrm{nM}$, for the adenosine (A), uridine (U), cytidine (C) and $N^{3}$-methyluridine (3meU) analogues.

${ }^{\mathrm{a}} \mathrm{The} \mathrm{K}_{\mathrm{i}}{ }^{\text {app }}$ values for adenosine derivatives were taken from our prior work[28].

${ }^{\mathrm{b}} 10 \mathrm{nM}$ ileRS, $2.5 \mathrm{nM}$ leuRS, and $0.5 \mathrm{nM}$ tyrRS were used in all reactions. The $\mathrm{K}_{\mathrm{i}}{ }^{\text {app }}$ values were calculated utilizing Greco-Hakala equation, maintaining the input enzyme concentration as a constant.

\section{Crystallography of inhibitor-bound aaRS complexes}

To obtain further insight into the relative inhibitory activity of the base-substituted intermediate analogues, X-ray crystallographic studies of the compounds in complex with their respective target aaRS were initiated. After extensive crystallization screening of recombinant leuRS and tyrRS from multiple bacterial species and subsequent optimization, diffracting crystals were obtained for E. coli tyrRS and $N$. gonorrhoeae leuRS. LeuRS from the latter gram-negative organism is a close homologue to the $E$. coli enzyme, with an overall sequence identity of $57 \%$. Further analysis shows a 92\% sequence identity (100\% similarity) for the residues within $6 \AA$ of LSA (see Supplementary Fig. S1). Therefore we can extrapolate the information obtained from the solved structures to the activity measurements obtained with $E$. coli leuRS.

Crystals of both aaRSs readily diffracted to $2.3 \AA$ or better, following soaking with the appropriate compounds 6a-c and 7a-c, or the analogous aminoacyl-sulfamoyl adenylate (see Supplementary Table 1 and 2). The resulting calculated electron density maps unambiguously allowed for the positioning of each compound. In the case of tyrRS, which presents itself as the natural homodimer in the crystallographic asymmetric unit, both active sites are occupied with the soaked inhibitors (see Supplementary Fig S2). Furthermore, for both enzymes, the refined structures gave an excellent realspace correlation coefficient (RSCC) for the modelled ligand confirming their overall quality (see Supplementary Table 2).

\section{Structures of inhibitor-tyrRS complexes}


In each of the four inhibitor-tyrRS complexes solved, both active sites of the dimer are substantially equivalent. For the four structures, superposition of the immediate ligand environment, defined as residues within $6 \AA$ of the compound, in chains A and B respectively reveal an all-atom RMSD between $0.275 \AA$ and $0.522 \AA$. Therefore, we will only focus on chain A of each structure for our description of the differences between the compounds. Here, pairwise comparison of the ligand environment in the YSA-bound structure with each of the pyrimidine-bound structures gives all-atom RMSDs not exceeding $0.2 \AA$. Since this value is even lower than the obtained equivalent all-atom RMSD between chains $A$ and $B$, it indicates that the measured difference in $\mathrm{K}_{\mathrm{i}}{ }^{\text {app }}$ between compounds 7a-c and YSA are the result of subtle structural differences. Reflecting the similarity of amino acid positions in the active sites of the four ligand-bound structures, examination of the inhibitor poses in the superposed models shows that the tyrosyl, sulfamoyl and ribose adopt nearly equivalent confirmations. We will therefore, limit our further description to the region surrounding the base moieties.

Within the perfect intermediate analog YSA, adenine makes a limited number of interactions with the active site. It is stacked between Gly50 of the $\mathrm{HIG}_{50} \mathrm{H}$-motif present in $\alpha$-helix 3 and a non-conserved branched amino acid, Leu227 (Fig. 3). The N6 and N1 atoms make backbone H-bond interactions with the carbonyl and amino group of Ile228, a backbone interaction conserved in all other class I aaRSs[28]. In comparison to YSA, the base of the three pyrimidine-substituted congeners 7a-c are sitting in the same plane as adenine, but distinct differences are observed. For YSC and YSU the respective bases adopt the same position as each other, sitting in the region that would be occupied by the imidazole ring of the adenine (Fig. 3). Both make Van der Waals interactions with Gly50, however, a likewise interaction with Leu227 is lost. In contrast to the adenine which forms two direct $\mathrm{H}$-bonds to the protein, only indirect H-bonding interactions via a water molecule, known as a water bridge, are observed for the pyrimidine bases. Both the natural bases make such a water bridge via the $\mathrm{O} 2$ atom, with the backbone $\mathrm{O}$ atom of Pro226. In the case of YSC, an extra water bridge between the N3 and the backbone N atom of Ile228 is observed. Modification of the N3 position with a methyl group changes the position of the base in the YS3meU bound structure. While it still sits in the same plane as observed for the uracil analog YSU, the methylated base is tilted $21.5^{\circ}$ into the adenine binding pocket, rotating around the C1'-O4 axis of the ribose, where the $\mathrm{O} 4$ atom shows a $2.3 \AA$ shift relative to the equivalent atom in YSU (see Supplementary Fig. S3A). The tilted position of the $N^{3}$ methyluracil resembles more the position of the adenine base, since the N1, C6 and C5 atoms of YS3meU are in the same position as N9, C8 and N7 of adenine and the methyl group lies in a position 
between the N1-C2 atoms of the adenine base (Fig. 3). In comparison to the two other pyrimidinebased congeners, no water molecules are observed in the proximity of the methyl-modified base. In addition Leu227 makes Van der Waals interaction with the methyl group. The relative rotation of the $N^{3}$-methyluracil is further driven by stabilizing Van der Waals interactions of the methyl group with the side chain of Val53 and the backbone of Pro226.

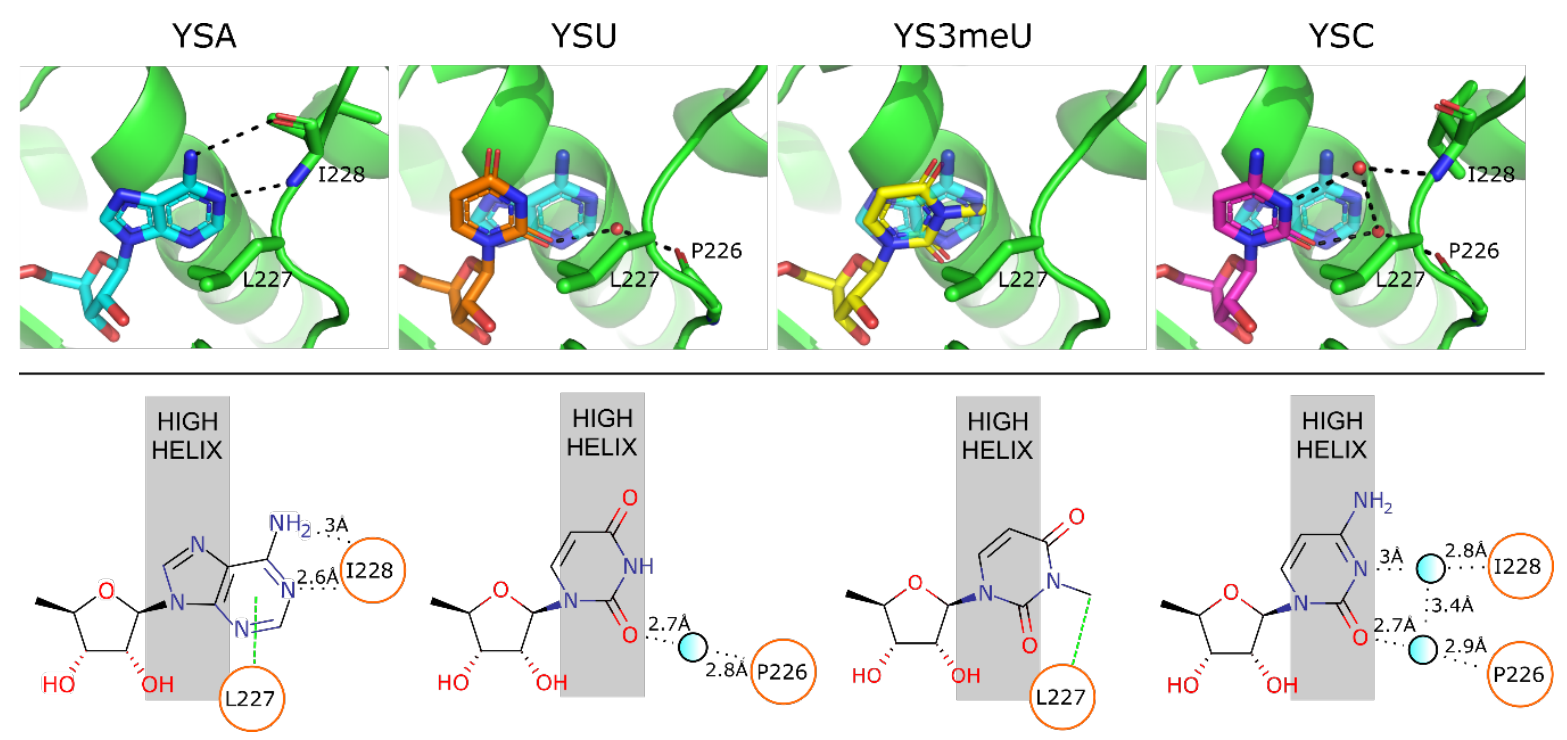

Fig. 3. Active site interactions of the tyrosyl sulfamoyl nucleoside congeners with $E$. coli tyrRS. Structures are shown in order of decreasing activity of the compound from left to right. Top; 3D representation of the base mediated interactions. Each ligand and the interacting protein residues are shown as a stick representation. The protein backbone is shown in green as a cartoon representation. H-bonds are shown as black dashes and water molecules as red spheres. For the three pyrimidinebased compounds the comparative position of the adenine base is shown as a transparent cyan stick representation. Bottom; 2D representation of the protein-compound interactions. H-bonds are shown as black dashes, stacking interactions as green dashes.

\section{Structures of inhibitor-leuRS complexes}

Our crystal structure of the $N$. gonorrhoeae leuRS with bound LSA reveals that the adenine base of the inhibitor is stacked between Gly51 of the $\mathrm{HIG}_{51} \mathrm{H}$-motif contain $\alpha$-helix and a branched hydrophobic amino acid, in this case, Met582. This stacking is conserved in all class I aaRS and also observed in our tyrRS bound structure with the respective analog. The base N6 amine interacts with the protein backbone of Met635, which is part of the class I conserved $\mathrm{KM}_{635}$ SKS loop. Furthermore, 
N1 and N6 are making H-bond interactions with the protein backbone of Val584, and the N3 atom interacts with the sidechain of Gln580 (Fig. 4).

Pairwise superposition of the protein environment within $6 \AA$ of the ligand in the LSA-bound structure in each of the structures with pyrimidine-based inhibitors gives all-atom RMSD close to $1.0 \AA$. This indicates more substantial changes in the vicinity of the inhibitor compared to the tyrRS complexes. Examination of the inhibitor poses in the superposed models shows that the leucyl, sulfamoyl and ribose moieties adopt equivalent confirmations and that structural differences between the inhibitors are base-related. We will therefore limit our further description to the base moieties.

The increase in RMSD of atoms surrounding the inhibitors is the result of two distinct differences. Firstly, none of the pyrimidine-substituted inhibitors make an H-bond with the backbone atoms of Met635, this results in this residue and the surrounding $\mathrm{KM}_{635}$ SKS loop being found $1.8 \AA$ away from the position observed in the LSA bound structure. Secondly, in all cases, the side chain of Met582 is rotated $90^{\circ}$ outward on the $C_{\beta}$ atom, reducing the stacking interaction with the different pyrimidine congeners (see Supplementary Fig. S3B). The base position of LS3meU resembles the position of the adenine base of LSA as the N1, C6 and C5 atoms of the former compound are in the same position as the N9, C8 and C7 of LSA (Fig. 4). The cytosine and uracil bases are rotated compared to the position of the bases of LS3meU and LSA. The cytosine base of LSC is rotated $24^{\circ}$ with respect to the C1'-O4 axis of LS3meU, resulting in a relative movement of the N4 atom by $2.3 \AA$ from the corresponding atom of LS3meU (see Supplementary Fig. S3C). The uracil base of LSU shows a similar movement as LSC. The position of the uracil and cytosine base relative to the ribose is different compared to the 3 -methyluracil base as the dihedral angle is $-131^{\circ}$ compared to $-152^{\circ}$ for LSC and LSU. To accommodate the position of the base of LSC and LSU, the sidechains of His49 and His52, part of the class I conserved $\mathrm{H}_{49} \mathrm{IGH}_{52}$-motif, are repositioned. Relative to the base position His52 is moved backwards $1.9 \AA$ and, in the case of LSU, the imidazole ring is additionally tilted $73^{\circ}$. The movement of His49 is more pronounced, with both the uracil and cytidine congeners the residue backbone atoms are shifted closer to the base moiety (1.6 $\AA$ for the $\mathrm{C}_{\alpha}$ atom), consequently the imidazole ring is displaced $3 \AA$ and rotated $72^{\circ}$, this rotation allows the N4 atom of LSC to form a hydrogen bond with the ND1 atom of His49. This latter interaction is nonexistent in the case of LSU as the imidazole ring is tilted $122^{\circ}$ compared to the position when LSC is present (see Supplementary Fig S3B). The space opened up by the rotation of the pyrimidine bases of LSC and LSU out of the pocket is filled by two water bridges. One is formed between the N3 atom and the 
backbone nitrogen of Val583, and the other one links the $\mathrm{O} 2$ atom with the backbone carbonyl group of Gly581 (Fig 4). Since the binding mode and the interactions are similar, it is not surprising that the $\mathrm{K}_{\mathrm{i}}^{\text {app }}$ for LSC and LSU are very close (Table 1).

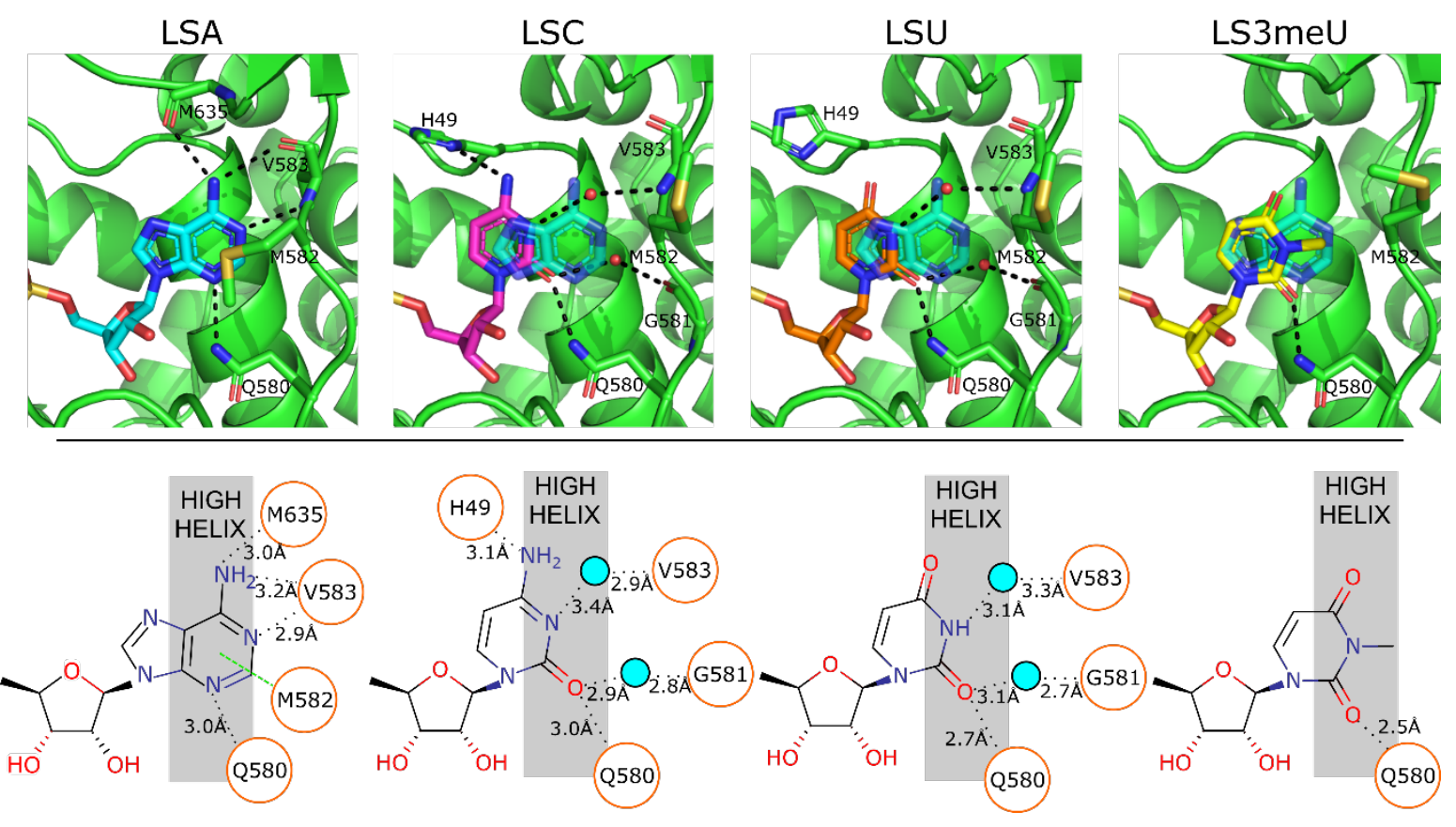

Fig. 4. Active site interactions of the leucyl-sulfamoyl nucleoside congeners with $N$. gonorrhoeae

leuRS. Structures are shown in order of decreasing activity of the compound from left to right. Top: 3D representation of the base-mediated interactions. Each ligand and the interacting protein residues are shown as a stick representation. The protein backbone is shown in green as a cartoon representation. H-bonds are shown as black dashes, and water molecules are shown as red spheres. For the three pyrimidine-based compounds the comparative position of the adenine base is shown as a transparent cyan stick representation. Bottom: 2D representation of the protein-compound interactions. H-bonds are shown as black dashes, stacking interactions as green dashes.

\section{Activity in S30 cell extracts}

As the next step, we have validated the potency of the synthesised inhibitors in cellular extract. To this end, respective aaRS activity was evaluated using an E. coli NCIB 8743 S30 extract pre-incubated with the inhibitors. The respective aaSA analogue was taken each time as a positive control (Fig 5A). These S30 extract experiments revealed a strong correlation with the inhibitory activity observed in the purified enzyme assays. For leuRS and ileRS, it was confirmed that cytidine and uridine showed more potent activity (5-14\% aa incorporation) compared to the $N^{3}$-methyluridine derivatives (17-34\% 
aa incorporation). Likewise, in line with the enzymatic results, YSU and YS3meU targeting tyrRS showed 37-62\% tyrosine incorporation and thus proved less inhibitory while YSC was devoid of inhibitory activity at the $250 \mathrm{nM}$ concentration. The aaSA analogues showed the most potent activity (0.05-1.8\% aa incorporation), in full agreement with the in vitro data.
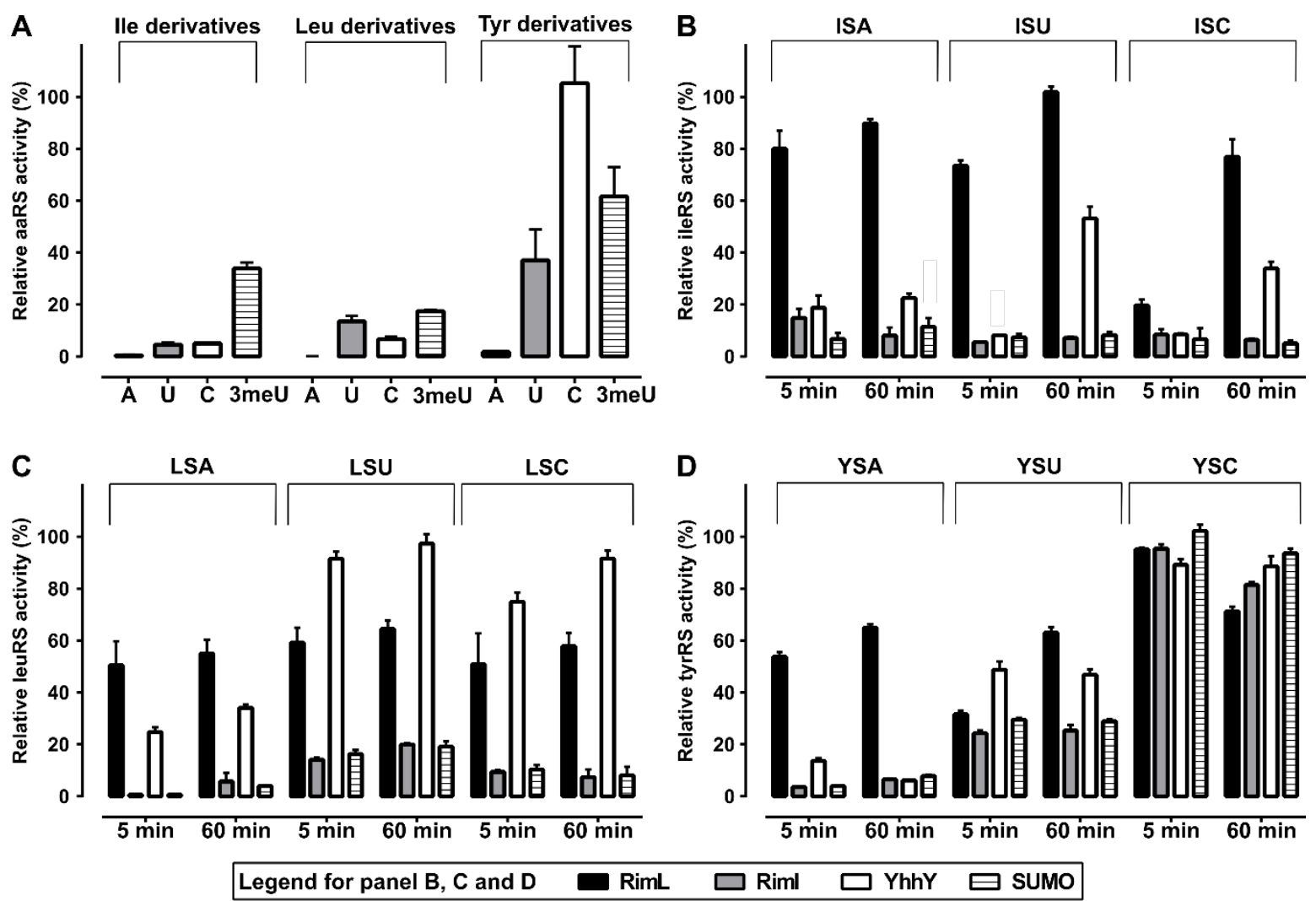

Fig. 5. Evaluation of aaRS inhibitors in cellular extracts (A). Relative inhibitory activity of aaSA analogues in E. coli NCIB 8743 cellular extracts. Activity was determined by measuring the transfer of the appropriate ${ }^{14} \mathrm{C}$-labeled amino acid to tRNA in the presence of $250 \mathrm{nM}$ of each compound [aaSA analogues (black bars), aaSU (grey bars), aaSC (white bars) and the aaS3meU (vertical line pattern)]. (B-D). Effect of different cellular extracts [5\% overexpressed (RimL / RimI / YhhY / SUMO) + 95\% E. coli BL21 (DE3) cellular extract] on the inhibitory activity of adenine, uracil and cytidine congeners targeting ileRS (B), leuRS (C) and tyrRS (D). The stated aaSA analogues were incubated at $25^{\circ} \mathrm{C}$, in the cell extract for 5 and 60 minutes, after which aliquots were taken and the aminoacylation activity was measured. The relative activity was determined by comparing to values of the extract measured in the absence of any inhibitor and assuming 100\% enzyme activity. The results correspond to an average of three experiments, with SD presented as error bars. 


\section{Inhibitory results in cellulo in the presence of NATs}

While our cell extract evaluations (Fig 3A) were in full agreement with the in vitro activity (Table 1), earlier in vitro data suggested ISU to be the best ileRS inhibitor, with ISC showing a similar inhibitory activity as ISA[16]. These discrepancies could have been caused by several phenomena which depend on the particular S30 cell extract and experimental conditions. The first potential possibility is an off-target binding of the inhibitors to other enzymes than aaRSs in a particular cellular assay. In particular, such off-target binding for ISA could have contributed to its lower apparent activity in the previously published experiments. The second possibility, also resulting in a changed inhibitory profile, is the loss of active compound due to chemical instability or their biochemical modification, such as resulting from the activity of $N$-acetyltransferases (NATs).

To evaluate the stability of the various sulfamoyl congeners in cellular extracts, we incubated these compounds with the S30 extract at $37^{\circ} \mathrm{C}$ for 48 hours, taking samples at different time points and assessing the ileRS activity in the radiotransfer assay. We did not observe any degradation of compounds, as the level of ileRS activity remained unaltered during the course of the experiment, where any decline correlated with a loss in activity of the enzyme as a result of extract instability during the prolonged incubation (see Supplementary Figs. S4 \& S5). These results contrast with earlier studies of DSA and LSA, in a wild-type E. coli cellular extract that showed a clear and rapid loss in inhibitor activity[13].

Next, acetylation of the $\alpha$-amine of aaSAs and processed microcin C is known to be the principal mechanism by which bacteria inactivate these compounds[13, 29]. The C-terminal domain of MccE, the enzyme responsible for acetylation of microcin $\mathrm{C}$, and the homologous bacterial N-terminal acetyltransferases RimL and YhhY, have been reported to be responsible for the acetylation of aaSA analogues requiring acetyl-CoA[13, 22]. We therefore hypothesized that upon supplementing the $E$. coli NCIB 8743 S30 extract with acetyl-CoA we could mimic the assay conditions used by Kazakov et al[13]. However, even upon addition of $0.5 \mathrm{mM}$ of acetyl-CoA, we did not detect any changes in the order of inhibitory activities (see Supplementary Fig. S6).

It has been described in the literature that NAT expression levels can vary dramatically depending on the strain and culture conditions[30]. This, therefore, prompted us to investigate whether the controlled overexpression of the aforementioned NATs affected the measured inhibitor activity. We decided to focus here only on the compounds carrying the natural bases cytosine or uracil, as the best activity was obtained for the uridine analogues among the isoleucyl sulfamoyl derivatives[16] and a recent paper reported that cytidine based compounds could also escape the GNAT based modification[23, 24]. We overexpressed E. coli RimL, YhhY, RimI and the His-tagged small 
ubiquitin-related modifier (SUMO) in the E. coli BL21(DE3) pLysS strain (see Supplementary Fig S7). RimI, a NAT that has been previously shown not to acetylate aaSAs was used to evaluate specificity. SUMO is a protein of similar molecular mass to the three NATs under study and was used as negative control to ensure that any observed loss of inhibitory activity of the compounds could not be associated with overexpression using the T7 RNA polymerase expression system or the presence of the recombinant plasmid in the cells. To improve signal in the assay the extract from the overexpression cell lines, which were grown to late stationary phase, were mixed with an extract prepared from the untransformed BL21(DE3) E. coli pLysS cells harvested in mid log-phase growth. In all experiments the reaction was supplemented with physiologically relevant amounts of acetylCoA to drive the acetylation reaction.

Each tested inhibitor was preincubated at $25^{\circ} \mathrm{C}$ with the different extracts and a sample taken at 5 min and 60 min for measurement of target aaRS activity (Fig 5B-D). For both the RimI and the SUMO extracts no significant effect on the activity of the inhibitor was observed. The relative pattern of the two tested pyrimidines, compared to each other and the respective adenosine analog, was the same for each target aaRS as was observed with the E. coli NCIB 8743 S30 extract (Fig 5A). For example, at the $250 \mathrm{nM}$ tested concentration YSA shows potent inhibitory activity and is better than YSU, while YSC shows no capacity to inhibit tyrRS as would be expected due to this compound being at a concentration below its $\mathrm{K}_{\mathrm{i}}^{\text {app }}$ (Fig 5A and 5D, Table 1). In contrast to the two control experiments, all studied compounds showed a significant decrease in inhibitory activity due to acetylation as a result of the presence of RimL in the cellular extract (Fig 5B-D). The isoleucyl and leucyl derivatives showed a rapid loss of inhibitory activity after 5 minutes, which remained constant over the following 55 minutes in the presence of RimL. Only ISC demonstrated slower inactivation by RimL, yet after 60 minutes of pre-incubation the same level of ileRS inhibition was obtained as observed for the two other base substituents (Fig 5B). For the isoleucyl derivatives preincubated in the RimL S30 extract, comparison of the 5 min preincubation timepoints shows that acetylation of ISA occurs more rapidly compared to the pyrimidine containing analogues. For ISU and ISA the remaining ileRS activity after 5 minutes is similar; however the $\mathrm{K}_{\mathrm{i}}{ }^{\text {app }}$ for ileRS of ISA is 29 -fold higher compared to ISU (Table 1). Therefore, to obtain these values, the relative amount of active non-acylated ISA molecules is lower compared to that of ISU after 5 minutes of incubation.

In the presence of YhhY, the isoleucyl derivatives showed apparent slower acetylation kinetics when compared to the RimL extract results, as after 5 minutes of preincubation no loss of inhibitory activity was observed. After 60 minutes of incubation a reduced inhibitory activity, yet better compared to the final levels in the RimL extract, was observed for all tested compounds (Fig. 5B). While the 
difference in kinetics can be attributed to a difference in expression levels between the two NATs (see Supplementary Fig. S7), YhhY demonstrates a bias for the two pyrimidine containing compounds as the remaining inhibitory activity is significantly less compared to ISA. (Fig. 5B). In the presence of RimL, all leucyl derivatives were rapidly but still incompletely acetylated (all tests showing around 50\% inhibitory activity), and this level remained constant over 60 minutes. Therefore, in view of the 70-fold difference in $\mathrm{K}_{\mathrm{i}}{ }^{\text {app }}$ values (Table 1), it can be concluded that the adenosine analogue is more readily acetylated than the cytidine congener. The behavior of the leuRS targeting compounds in the presence of YhhY is overall similar to what was seen with the ileRS compounds. In particular the remaining inhibitory levels of LSC and LSU are lower compared to LSA after 60 minutes of preincubation in the cell extract. However, compared to the isoleucyl congeners, YhhY acetylated the leucyl-based pyrimidine substitutions much faster, as after 5 minutes of incubation almost a complete eradication of inhibitory activity is observed. (Fig 5C). Next, YSA and YSU analogues showed some increase in acetylation over 60 minutes upon treatment with RimL extract, whereas YSC was inactive from the start as shown by the inactivity in the RimI and SUMO extracts, and correlating with the fact that the $\mathrm{K}_{\mathrm{i}}{ }^{\text {app }}$ is above the used inhibitor concentration (Fig. 5D). Most remarkable however, is the somewhat higher inhibitory effect of YSU over YSA, after 5 minutes in the RimL extract, while being equally inhibitory after 1 hour. This result again points to the fact that RimL more rapidly acetylates adenine-containing compounds over pyrimidine congeners. On the contrary, YhhY seems to prefer the latter as no reduction in inhibitory activity is observed for YSA while YSU shows a statistically significant reduction in the capacity to inhibit tyrRS. Next to the base moiety the amino acid part on the inhbitors also seems to influence the activity of the NAT, since in the presence of YhhY, the inhibitory activity of YSU is higher compared to the isoleucyl and leucyl analogues (Fig 5D). The tyrosyl moiety also affects the activity of RimL as after 5 minutes of incubation YSU is less inactivated compared to the latter compounds. In summary, we established that RimL can deactivate all tested compounds, with the enzyme showing a preference for adenine containing congeners, while the corresponding pyrimidine derivatives are, relatively, less affected. However the pyrimidine congeners suffer more from the presence of YhhY, as the reduction of inhibitory activity is observed faster and the final levels of remaining activity are less compared to the equivalent adenine containing compounds.

\section{DISCUSSION}

Aminoacyl-tRNA synthetases have been recognized as promising targets for the development of new antimicrobials[1, 4, 19]. This is most clearly evidenced by the clinical application of the natural 
product mupirocin (Bactroban), a competitive inhibitor that specifically targets bacterial ileRS[31]. Despite this, attempts to target other members of this conserved family of enzymes have resulted in limited success. Replicating the mode of action of mupirocin, bisubstrate inhibitors that typically target the enzyme amino acid and ATP binding sites simultaneously, have proven to have the most potent activity. Amongst the many scaffolds that have been described, aminoacyl-sulfamoyl adenosines, non-hydrolysable mimetics of the enzymatic intermediate (Fig 1a and 1c) have familywide activity[1]. Previously it was shown that pyrimidine base-containing isoleucyl-sulfamoyl nucleoside analogues had a strong ileRS inhibitory potency. The activity of these inhibitors in whole cell lysates was even superior to that of the adenine-based compound[16]. The latter result was somewhat surprising considering the reported specificity of aaRSs for ATP as a substrate over other nucleoside triphosphates[32].

In the current study, we have systematically evaluated the activity of a series of pyrimidinesubstituted non-hydrolysable intermediate analogues against ileRS and two other class I enzymes, leuRS and tyrRS. In total nine compounds, corresponding to three different pyrimidines for each tested aaRS were successfully synthesized and their inhibitory activity was investigated in vitro. Using the appropriate isolated enzyme from E. coli, seven of the inhibitors, the exceptions being YSC and IS3meU, demonstrated a $\mathrm{K}_{\mathrm{i}}^{\text {app }}$ above $150 \mathrm{nM}$, with the best inhibitor LSC having a value below 10 nM (Fig. 2 and Table 1). Therefore, substitution of the adenine base with a pyrimidine is not too destructive for inhibitors targeting class I aaRS members.

To obtain a molecular understanding of the inhibitory mechanism of the pyrimidine congeners and to explain the pronounced differences in activity between them, crystallization trials for all targeted aaRSs supplemented with the inhibitors were undertaken. High-resolution structures were obtained for E. coli tyrRS and N. gonorrhoeae leuRS bound to the different synthesized inhibitors providing insight into the specific enzyme-ligand interactions. Crystal structures for both enzymes in complex with a non-hydrolysable intermediate analogue have been reported before[33-35]. The new structures confirm the previously observed interactions with the amino acid and ribose, where the notable differences are related to residues in the active site that surround the base moiety and the positioning of the different pyrimidines relative to each other and the adenine congener.

In all class I aaRSs, the canonical base is found sandwiched between the highly conserved HIGHmotif containing $\alpha$-helix and a hydrophobic residue, while making a number of $\mathrm{H}$-bond interactions with the protein backbone (Fig. 3 and 4)[28]. Importantly, our newly established structures reveal that while the pyrimidine bases go to the same pocket, they do not form direct H-bonds to the protein. Instead, H-bond interactions are only realized via ordered water molecules, i.e. water bridges. This 
general observation is likely to explain the lesser potency of the pyrimidine-based analogues compared to the original adenine-containing compounds.

In addition, the obtained aaRS structures with the respective pyrimidine-based compounds reveal subtle structural differences in the binding mode of the base. At the same time, observation of these structural features appears to have only a limited predictive power with respect to the observed inhibitory activity. For the pyrimidine analogues that demonstrated the best inhibition, binding to either aaRS is accompanied by the formation of one or two water bridges. However, the effect of water recruitment on the potency of the compound seems to be different between the enzymes. In the case of leuRS, the bases of LSU and LSC coordinate two water molecules and are more effective compounds than LS3MeU where the additional methyl group prevents water binding. In contrast, a similar number of bridging water molecules are observed in the tyrRS-YSC structure, however the $\mathrm{K}_{\mathrm{i}}^{\mathrm{app}}$ for this compound is above $1 \mu \mathrm{M}$. This value is 34-fold higher than that of YSU, which only coordinates one water molecule in the bound structure (Fig. 3). Next to the biophysical parameters affecting ligand efficiency, the ability of the compounds to induce conformational changes in the active site differs between leuRS and tyrRS. In the leuRS structure bound to LSA, an additional stacking interaction mediated by Met582 is observed with the canonical purine group, and the downstream conserved $\mathrm{KM}^{635}$ SKS loop moves towards the base to interact with the hydrogens of the N6 atom resulting in a more compact pocket. In contrast all pyrimidine congeners targeting leuRS do not induce these changes (Fig. 4). In contrast, in the ligand bound tyrRS structures the positioning of residues in the active site around the base are similar for both the adenine and the three pyrimidines (Fig. 3).

The class I aaRS family consists of five structurally defined subclasses[32]. LeuRS and ileRS belong to subclass IA alongside methionyl- and valyl-tRNA synthetase, while the dimeric tyrRS is a member of subclass IC that also includes tryptophanyl-tRNA synthetase[36]. Since we observed distinct differences in the order of inhibitory activity of the pyrimidine congeners between the studied aaRS, that reflect this structural classification (Table 1), cross-class extrapolation of the present results should be limited to each aaRS subclass. The majority of the remaining aaRSs, such as arginyl, glutaminyl- and glutamyl-tRNA synthetase (gluRS) are unable to catalyze the formation of the aminoacyl-adenylate intermediate in the absence of tRNA, as a conformational change induced by binding of the latter macromolecule is necessary for correct active site arrangement[37-39]. Despite this requirement, non-hydrolysable intermediate analogues have been shown to inhibit these enzymes[40-42]. In particular, the aminoalkyl-adenylate intermediate analog of Glu-AMP has a $\mathrm{K}_{\mathrm{i}}$ of $3 \mu \mathrm{M}$. Substitution of the adenine in this inhibitor scaffold with various pyrimidines resulted in a 
three order of magnitude loss of inhibitory activity[43]. Therefore, there is a high probability that for the remaining subclasses of class I the equivalent pyrimidine congeners will also demonstrate a reduced activity compared to the adenine analog, although the relative response between the different pyrimidines is difficult to predict, particularly in terms of the subtle differences in recruiting water molecules for bridging interactions or the induction of conformational changes within the active site. Importantly, both the in vitro biochemical and structural data presented here are in agreement in that all tested pyrimidines demonstrate lower inhibitor activity than the canonical aaSA. Moreover, for all twelve compounds tested, cell extract experiments fully confirmed the relative potency observed in experiments with isolated aaRSs.

Upon activity determination in whole cell lysates, some subtle differences with previous findings remain[16]. Since a vast plethora of enzymes are present and active at different concentrations within such an extract, the compounds could be prone to enzymatic modification or degradation to varying degrees as seen for other antimicrobials[44-46]. Primary amines of antimicrobial agents are known to be targets for enzymatic modification leading to resistance. Specifically, Kazakov et al. previously reported that non-hydrolysable adenylates are substrates for the GNATs RimL and YhhY[13]. As the levels of these host enzymes and their substrate acetyl-CoA can vary considerably in cells, we overexpressed them in E. coli and evaluated their effect on the pyrimidine-based aaRS inhibitors in cellular extracts. In line with our hypothesis, we observed that all congeners can be deactivated by RimL and YhhY (Fig. 5B-D). However, with RimL adenine is clearly preferred over the three pyrimidines. In this case acetylation of the $\alpha$-amino group results in a parity of the inhibitory activity of the adenine containing compounds with the pyrimidine analogues in the bacterial extract following 60 minutes of incubation. In contrast, YhhY does not seem to have a base preference, although there appears to be a larger discrepancy between the attached amino acid, with leucine more prone to modification over its isomer and tyrosine. These results are in agreement with previous studies that observed that a large number of aaSAs were inactivated by RimL independent of the attached amino acid, while only non-polar amino acids were affected by YhhY[13].

In particular, we have studied the effect of the MccE enzyme that has been identified in the operon responsible for the production of the Trojan-horse antibiotic microcin C7, a natural non-hydrolysable intermediate analog targeting aspRS[22]. Similarly to the host GNATs, the C-terminal domain of MccE has shown to acetylate the $\alpha$-amine of the active component, providing self-resistance to the producing strain. Structures of this domain in complex with non-hydrolysable adenylate analogues have been solved, and show that the main determinant for binding is the adenine base[47]. Specifically, the purine is sandwiched between two aromatic side chains resulting in strong but non- 
specific $\pi$ - $\pi$ stacking interactions. Since the base moiety of the presently synthesized compounds partially replicates the adenine stacking interactions bound to the respective aaRS enzyme (Figs. 3 and 4), it is likely that they also can form the same $\pi-\pi$ stacking interaction in MccE, or the homologous RimL and YhhY enzymes. Interestingly a carboxymethylated cytidine-based microcin C analog can escape MccE catalysed acetylation, retaining its antibacterial activity while the equivalent adenine and cytosine congeners were inactivated. This suggests that approptiate modification of the heterocyclic group can facilitate in avoiding this natural resistance mechansim[23]. Understanding how the different GNATs bind the synthesised molecules, providing knowledge of both the role of the base and the amino acid in recognition would be beneficial in the further development of aaSA analogues as antimicrobials.

Combined, comparative biochemical evaluation and structural studies of the synthesized pyrimidine congeners highlight the surprisingly limited number of interactions mediated by the class I aaRSs with the base moiety and can help explain the promiscuity of this aaRS class with other competitive inhibitors. For example, the ester-containing aliphatic chain of mupirocin effectively substitutes for the adenine base, despite having no chemical resemblance (Fig. 1b). Similarly, Cubist Pharmaceuticals reported compounds where the base was replaced by a tetrazole or triazole group, targeting ileRS[19] and leuRS[18], respectively. Moreover, recently, Charlton et al. reported modified N-leucinyl benzenesulfonamides targeting leuRS[15]. This is only a small overview of all available compounds, yet what they have in common is strong inhibitory activity in spite of a large variety of base modifications. Unfortunately, except for the mupirocin-ileRS complex[31], limited structural information is available for these chemical entities. Our obtained crystallographic data provide insight, for the first time, into the structure of class I aaRSs bound to base modified inhibitors. While these protein-ligand structures can be employed for further drug development, the current work also highlights the importance of evaluating the naturally occurring resistance mechanisms. The majority of reported aaRS inhibitors employ an amino acid to provide selectivity, this though is likely the Achilles' heel of such entities and as such all compounds should be evaluated against the NATs of the target organism.

\section{EXPERIMENTAL SECTION}

\subsection{Materials and methods}

Reagents and solvents were purchased from commercial suppliers and used as provided unless indicated otherwise. DMF and THF were of analytical grade and were stored over $4 \AA$ molecular sieves. All other solvents used for reactions were analytical grade and used as provided. Reactions were carried out in oven-dried glassware under a nitrogen atmosphere with stirring at room 
temperature unless indicated otherwise. ${ }^{14} \mathrm{C}$-radiolabeled amino acids and scintillation liquid were purchased from Perkin Elmer. ${ }^{1} \mathrm{H}$ and ${ }^{13} \mathrm{C}$ NMR spectra of the compounds dissolved in $\mathrm{CDCl}_{3}$, $\mathrm{CD}_{3} \mathrm{OD}$, DMSO- $d_{6}$ or $\mathrm{D}_{2} \mathrm{O}$ have recorded on a Bruker Ultra Shield Avance $300 \mathrm{MHz}, 500 \mathrm{MHz}$ or when needed at $600 \mathrm{MHz}$ spectrometers. The chemical shifts are expressed as $\delta$ values in parts per million (ppm), using the residual solvent peaks $\left(\mathrm{CDCl}_{3}:{ }^{1} \mathrm{H} 7.26 \mathrm{ppm} ;{ }^{13} \mathrm{C}, 77.16 \mathrm{ppm}\right.$; DMSO: ${ }^{1} \mathrm{H}$, 2.50 ppm; ${ }^{13} \mathrm{C}$, 39.52 ppm; HOD: ${ }^{1} \mathrm{H}, 4.79 \mathrm{ppm}$; $\mathrm{CD}_{3} \mathrm{OD}:{ }^{1} \mathrm{H}, 3.31 \mathrm{ppm} ;{ }^{13} \mathrm{C}, 49.00 \mathrm{ppm}$ ) as a reference. Coupling constants are given in Hertz $(\mathrm{Hz})$. The peak patterns are indicated by the following abbreviations: $\mathrm{bs}=$ broad singlet, $\mathrm{d}=$ doublet, $\mathrm{m}=$ multiplet, $\mathrm{q}=$ quadruplet, $\mathrm{s}=$ singlet and $\mathrm{t}=$ triplet. High-resolution mass spectra were recorded on a quadrupole time-of-flight mass spectrometer (Q-Tof-2, Micromass, Manchester, UK) equipped with a standard ESI interface; samples were infused in 2-propanol $/ \mathrm{H}_{2} \mathrm{O}(1: 1)$ at $3 \mu \mathrm{L} \cdot \mathrm{min}^{-1}$. For TLC, precoated aluminium sheets were used (Merck, Silica gel $60 \mathrm{~F}_{254}$ ). The spots were visualized by UV light at $254 \mathrm{~nm}$. Column chromatography was performed on ICN silica gel 60A 60-200 $\mu \mathrm{m}$. Final products were purified using a C-18 $110 \AA$ column connected to a Shimadzu SPD-20A HPLC and Shimadzu SPD-20A detector. Eluent compositions are expressed as v/v. Recordings were performed at $254 \mathrm{~nm}$ and $214 \mathrm{~nm}$. Analytical data are only provided for all new compounds.

\subsection{Chemical synthesis of the intermediates and final compounds}

\subsubsection{General procedure for synthesis of 2 ',3',5'-tri- $O$-TBDMS nucleosides (2a \& $2 b$ )}

Following the protocol as described the persilylated nucleosides were obtained and analytical data for the uridine and cytidine analogues corresponded to published literature data[16, 48, 49].

4.2.1.1 2',3',5'-tri-O-tert-butyldimethylsilyl- $N^{3}$-Methyluridine (2c).

Following a described protocol[25], the persilylated uridine (1 equivalent) was suspended in a mixture of DMF: acetone (1:1), along with $\mathrm{K}_{2} \mathrm{CO}_{3}$ (4 equivalent). MeI (1.5 equivalent) was added dropwise to the suspension, and the mixture was stirred overnight. After completion of reaction, solvents were evaporated, and the residue was partitioned between ethyl acetate and water. The layers were separated, and the aqueous layer was extracted with ethyl acetate. The combined organic layers were washed with brine, dried over sodium sulfate, filtered and evaporated to yield an oily residue which was purified by silica gel chromatography and the compound was eluted with 5-10\% EtOAc: Hexane in 81\% yield. ${ }^{1} \mathrm{H}$ NMR (300 MHz, $\mathrm{CDCl}_{3}$ ) 0.06-0.12 (6s, $18 \mathrm{H}, \mathrm{CH}_{3}-\mathrm{Si}$ ), 0.88-0.93 (3s, 27H, ${ }^{t} \mathrm{Bu}-\mathrm{CH}_{3}$ ), 3.32 (s, 3H, N-CH $), 3.75$ (d, 1H, $J=11.9$ Hz, H-5'a ), 3.98 (d, 1H, $J=11.9$ Hz H-5'b ), 4.02-4.09 (m, 3H, H-4', H-3', H-2'), 5.71 (d, 1H, J = 8.1 Hz, H-5), 5.88 (bs, 1H, H-1'), 7.98 (d, 1H, J $=8.2 \mathrm{~Hz}, \mathrm{H}-6), 8.66(\mathrm{~s}, 1 \mathrm{H}, \mathrm{NH}) .{ }^{13} \mathrm{C}$ NMR $\left(75 \mathrm{MHz}, \mathrm{CDCl}_{3}\right) \delta-5.9\left(\mathrm{CH}_{3}-\mathrm{Si}\right),-5.7\left(\mathrm{CH}_{3}-\mathrm{Si}\right),-5.2$ $\left.\left(\mathrm{CH}_{3}-\mathrm{Si}\right),-5.1\left(\mathrm{CH}_{3}-\mathrm{Si}\right),-4.9\left(\mathrm{CH}_{3}-\mathrm{Si}\right),-4.6\left(\mathrm{CH}_{3}-\mathrm{Si}\right), 17.6\left({ }^{\mathrm{t}} \mathrm{Bu} \mathrm{C}\left(\mathrm{CH}_{3}\right)\right)_{3}\right), 17.7\left({ }^{\mathrm{t}} \mathrm{Bu} \mathrm{C}\left(\mathrm{CH}_{3}\right)_{3}\right)$, 
18.2 (' $\left.{ }^{\mathrm{t} u ~ C}\left(\mathrm{CH}_{3}\right)_{3}\right), 25.4$ (' $\left.{ }^{\mathrm{B} u ~ C H} \mathrm{CH}_{3}\right), 25.5$ ('Bu CH$), 25.69$ ('Bu $\left.\mathrm{CH}_{3}\right), 27.2\left(\mathrm{CH}_{3}-\mathrm{N}\right), 61.4(\mathrm{C}-5$ '), 70.3 (C-3'), 75.9 (C-2'), 83.9 (C-4'), 89.2 (C-1'), 100.9 (C-5), 137.7 (C-6), 150.7 (C-2), 162.7 (C-4). HRMS [ESI] m/z: calcd. for $\mathrm{C}_{28} \mathrm{H}_{57} \mathrm{~N}_{2} \mathrm{O}_{6} \mathrm{Si}_{3}\left([\mathrm{M}+\mathrm{H}]^{+}\right)$: 601.3519, found: 601.3529 .

\subsubsection{General procedure for selective 5 '-desilylation (3a-c)}

The procedure reported in reference 15 was followed to obtain the 5'-desilylated compounds. The uridine and cytidine analogues data corresponded to published literature data[16].

4.2.2.1. 2',3',-di-O- tert-butyldimethylsilyl- $N^{3}$-methyluridine (3c).

The compound was eluted through column chromatography using 20-30\% EtOAc: Hexane in 73\% yield. ${ }^{1} \mathrm{H}$ NMR (300 MHz, $\left.\mathrm{CDCl}_{3}\right) \delta 0.03$ (s, 3H, $\mathrm{CH}_{3}-\mathrm{Si}$ ), 0.06 (s, 3H, $\mathrm{CH}_{3}-\mathrm{Si}$ ), 0.08 (s, 6H, $\mathrm{CH}_{3}$ -Si), 0.88 (s, 9H, ${ }^{\mathrm{t}} \mathrm{Bu} \mathrm{CH} \mathrm{CH}_{3}$ ), 0.91 (s, 9H, ${ }^{\mathrm{t}} \mathrm{Bu} \mathrm{CH}_{3}$ ), 3.71 (d, $1 \mathrm{H}, J=12.5 \mathrm{~Hz} \mathrm{H}-5$ 'a ), 3.94 (d, $1 \mathrm{H}, J$ $=12.5 \mathrm{~Hz} \mathrm{H}-5$ 'b ), 4.08 (bs, 1H, H-3'), 4.15-4.18 (m, 3H, H-4'), 4.53-4.57 (m,H-2'), 5.46 (d, 1H, $J=$ $8.2 \mathrm{~Hz}, \mathrm{H}-1$ ') 5.29 (d, 1H, $J=8.1 \mathrm{~Hz}, \mathrm{H}-5), 7.63$ (d, $1 \mathrm{H}, J=8.1 \mathrm{~Hz}, \mathrm{H}-6), 8.78$ (bs, $1 \mathrm{H}, \mathrm{NH}) .{ }^{13} \mathrm{C}$ NMR (75 MHz, $\left.\mathrm{CDCl}_{3}\right) \delta$-5.3 $\left(\mathrm{CH}_{3}-\mathrm{Si}\right),-5.1\left(\mathrm{CH}_{3}-\mathrm{Si}\right)$, $-4.0\left(\mathrm{CH}_{3}-\mathrm{Si}\right),-4.8\left(\mathrm{CH}_{3}-\mathrm{Si}\right), 17.6\left({ }^{\mathrm{t}} \mathrm{Bu}\right.$ $\left.\mathrm{C}\left(\mathrm{CH}_{3}\right)_{3}\right), 17.7\left({ }^{\mathrm{t}} \mathrm{Bu} \mathrm{C}\left(\mathrm{CH}_{3}\right)_{3}\right), 25.4$ ( $\left.{ }^{\mathrm{B} u ~ C H} \mathrm{CH}_{3}\right), 25.5\left({ }^{\mathrm{t}} \mathrm{Bu} \mathrm{CH}_{3}\right), 27.3\left(\mathrm{CH}_{3}-\mathrm{N}\right), 61.4(\mathrm{C}-5$ ') $71.5(\mathrm{C}-$ 30), 73.0 (C-20), 86.0 (C-40), 84.5 (C-10), 101.2 (C-5), 140.6 (C-6), 150.1 (C-2), 162.5 (C-4). HRMS [ESI] m/z: calcd. for $\mathrm{C}_{22} \mathrm{H}_{43} \mathrm{~N}_{2} \mathrm{O}_{6} \mathrm{Si}_{2}\left([\mathrm{M}+\mathrm{H}]^{+}\right)$487.2654, found: 487.2653 .

\subsubsection{General procedure for synthesis of the respective 5'-O-sulfamoyl nucleosides (4a-c)[16]}

The reported procedure was followed to get sulfamoylated compounds; data for uridine and cytidine analogues corresponded to published literature data[16].Care should be taken to use a fresh bottle of chlorosulfonyl isocyanate to avoid formation of the carbamoylated side product.

4.2.3.1. 2',3'-di-O-tert-butyldimethylsilyl-5'-O-sulfamoyl- $N^{3}$-methyluridine (4c).

The compound was eluted through column chromatography using 30-70\% EtOAc: Hexane in 68\% yield. ${ }^{1} \mathrm{H}$ NMR (300 MHz, $\mathrm{CDCl}_{3}$ ) $\delta$ 0.08-0.09 (4s, $12 \mathrm{H}, \mathrm{CH}_{3}-\mathrm{Si}$ ), 0.88-0.90 (s, 18H, $\mathrm{BBu}_{-} \mathrm{CH}_{3}$ ), 3.30 (s, 3H, -N-Me), 4.03-4.07 (m, 1H, H-5'a), 4.23-4.27 (m, 2H, H-5’b, H-4'), 4.30-4.35 (m, 1H, H-2'), 4.47-4.52 (m, 1H, H-3'), 5.59 (s, 2H, -SONH 2 ), 5.69 (d, 1H, $J=3.5$ Hz, H-1'), 5.82 (d, 1H, $J=8.1$ $\mathrm{Hz}, \mathrm{H}-5), 7.58$ (d, 1H, $J=8.2 \mathrm{~Hz}, \mathrm{H}-6) .{ }^{13} \mathrm{C} \mathrm{NMR}\left(75 \mathrm{MHz}, \mathrm{CDCl}_{3}\right) \delta-5.3\left(\mathrm{CH}_{3}-\mathrm{Si}\right), 5.2\left(\mathrm{CH}_{3}-\mathrm{Si}\right)$, -4.9 ( $\left.\mathrm{CH}_{3}-\mathrm{Si}\right)$, -4.6 ( $\left.\mathrm{CH}_{3}-\mathrm{Si}\right), 17.7$ ( $\left.{ }^{\mathrm{B}} \mathrm{Bu} \mathrm{C}\left(\mathrm{CH}_{3}\right)_{3}\right), 25.4$ ( $\left.{ }^{\mathrm{t}} \mathrm{Bu} \mathrm{CH}_{3}\right), 25.4$ ( $\left.{ }^{\mathrm{B}} \mathrm{Bu} \mathrm{CH}_{3}\right), 67.9$ (C-5'), 70.4 (C-3’), 74.4 (C-2'), 80.9 (C-4’), 91.3 (C-1’), 101.2 (C-5), 138.0 (C-6), 150.6 (C-2), 162.9 (C-4). HRMS [ESI] m/z: calcd. for $\mathrm{C}_{22} \mathrm{H}_{44} \mathrm{~N}_{3} \mathrm{O}_{8} \mathrm{SSi}_{2}\left([\mathrm{M}+\mathrm{H}]^{+}\right)$566.2382, found: 566.2394. 


\subsubsection{General procedure for synthesis of 5 '-O-( $N$-L-aminoacyl)-sulfamoyl-nucleosides [5-7(a- c)]}

The coupling of various activated amino acids with sulfamoylated nucleosides was carried out as described[8, 16]. The uridine and cytidine analogues (5a and $5 \mathbf{b})$ data corresponded to published literature data. Final product was eluted through column chromatography initially using MeOH: DCM to get the intermediate and finally through HPLC using acetonitre:water to get desired compounds as white fluffy solid in 30-82\% yields (combined yields from coupling to final deprotection).

4.2.4.1. 5'-O-( $N$-L-isoleucyl)-sulfamoyl- $N^{3}$-methyluridine (5c)

The final compound was obtained in 74\% yield. ${ }^{1} \mathrm{HNMR}\left(300 \mathrm{MHz}, \mathrm{D}_{2} \mathrm{O}\right) \delta 0.91(\mathrm{t}, 3 \mathrm{H}, J=7.4 \mathrm{~Hz}$, Ile- $\delta-\mathrm{CH}_{3}$ ), 1.02 (d, 3H, $J=7.0 \mathrm{~Hz}$, Ile- $\gamma-\mathrm{CH}_{3}$ ), $1.24-1.30$ (m, $1 \mathrm{H}$, Ile- $\gamma-\mathrm{CH}_{2} \mathrm{Ha}$ ), $1.43-1.52$ (m, $1 \mathrm{H}$, Ile- $\gamma-\mathrm{CH}_{2} \mathrm{Hb}$ ), 2.03-2.04 (m, 1H, Ile- $\beta-\mathrm{CH}$ ), 3.28 (s, 3H, N3-Me), 3.79 (d,1H, J = 4.1 Hz, Ile- $\alpha$ CH), 4.30-4.49 (m, 5H, H-5'a, H-5'b, H-4', H-3', H-2' ), 5.94 (d, 1H, J = 3.5 Hz, H-1') 6.00 (d, 1H, J $=8.1 \mathrm{~Hz}, \mathrm{H}-5), 7.80(\mathrm{~d}, 1 \mathrm{H}, J=8.1 \mathrm{~Hz}, \mathrm{H}-6) .{ }^{13} \mathrm{C}$ NMR $\left(75 \mathrm{MHz}, \mathrm{D}_{2} \mathrm{O}\right) \delta 10.6$ (Ile- $\left.\delta-\mathrm{CH}_{3}\right), 14.2$ (Ile- $\gamma-\mathrm{CH}_{3}$ ), 23.8 (Ile- $\delta$ - $\mathrm{CH}_{2}$ ), $\delta 27.4$ (N3-Me), 36.1 (Ile- $\beta-\mathrm{CH}$ ), 59.5 (Ile- $\left.\alpha-\mathrm{CH} 2\right), 68.2$ (C-5'), 68.9 (C-3'), 73.3 (C-2'), 81.1 (C-4'), 89.7 (C-1'), 101.4 (C-5), 139.0 (C-6), 151.7 (C-2), 165.1 (C-4), 173.7 (C=O, Ile). HRMS [ESI] m/z: calcd. for $\mathrm{C}_{16} \mathrm{H}_{25} \mathrm{~N}_{4} \mathrm{O}_{9} \mathrm{~S}$ ([M-H]') 449.1347 found, 449.1355.

4.2.4.2. 5'-O-(N-L-leucyl)-sulfamoyl-cytidine (6a).

The final compound was obtained in 58\% yield. ${ }^{1} \mathrm{HNMR}\left(300 \mathrm{MHz}, \mathrm{D}_{2} \mathrm{O}\right) \delta$ 0.93-0.98(m, 6H, Leu$\left.\delta-\mathrm{CH}_{3}\right), 1.66-1.81\left(\mathrm{~m}, 3 \mathrm{H}\right.$, Leu- $\left.\beta-\mathrm{CH}_{2} \& 1 \mathrm{H}-\mathrm{Leu}-\gamma-\mathrm{CH}\right), 3.79-3.84(\mathrm{~m}, 1 \mathrm{H}$, Leu- $\alpha-\mathrm{CH}$ ), 4.28-4.50 (m, 5H, H-5'a, H-5'b, H-4' H-3', H-2'), 5.97 (d, 1H, $J=3.9$ Hz, H-1'), 6.12 (d, 1H, J= 7.6 Hz, H-5), $7.85(\mathrm{~d}, 1 \mathrm{H}, J=7.6 \mathrm{~Hz}, \mathrm{H}-6) .{ }^{13} \mathrm{C}$ NMR $\left(75 \mathrm{MHz}, \mathrm{D}_{2} \mathrm{O}\right) \delta 20.7\left(\mathrm{Leu}-\delta-\mathrm{CH}_{3}\right), 21.6\left(\mathrm{Leu}-\gamma-\mathrm{CH}_{3}\right), 23.8$ (Leu- $\gamma$-CH), 40.0 (Leu- $\beta-\mathrm{CH}_{2}$ ), 54.0 (Leu- $\left.\alpha-\mathrm{CH}\right), 67.7$ (C-5'), 69.0 (C-3'), 73.7(C-2'), 81.0 (C-4'), 89.5 (C-5), 96.1 (C-1'), 141.0 (C-6), 157.3 (C-2), 165.9 (C-4), 176.3 (C=O, Leu). HRMS [ESI] m/z: calcd. for $\mathrm{C}_{15} \mathrm{H}_{24} \mathrm{~N}_{5} \mathrm{O}_{8} \mathrm{~S}$ ([M-H] $\left.]^{-}\right)$434.1351: found, 434.1351.

4.2.4.3. 5'-O-(N-L-leucyl)-sulfamoyl-uridine (6b).

The final compound was obtained in 82\% yield. ${ }^{1} \mathrm{HNMR}\left(300 \mathrm{MHz}, \mathrm{D}_{2} \mathrm{O}\right) \delta$ 0.94-0.98(m, 6H, Leu$\delta-\mathrm{CH}_{3}$ ), 1.67-1.81 (m, 3H, Leu- $\left.\beta-\mathrm{CH}_{2} \& 1 \mathrm{H}-\mathrm{Leu}-\gamma-\mathrm{CH}\right), 3.84-3.89$ (m, $1 \mathrm{H}$, Leu- $\alpha-\mathrm{CH}$ ), 4.32-4.44 (m, 5H, H-5'a, H-5'b, H-4' H-3', H-2'), 5.94-5.97 (m, 2H, H-1', H-5), 7.82 (d, 1H, J = 7.6 Hz, H-6). ${ }^{13} \mathrm{C}$ NMR (75? MHz, $\left.\mathrm{D}_{2} \mathrm{O}\right) \delta 20.6\left(\mathrm{Leu}-\delta-\mathrm{CH}_{3}\right), 21.6\left(\mathrm{Leu}-\delta-\mathrm{CH}_{3}\right), 23.7\left(\mathrm{Leu}-\gamma-\mathrm{CH}_{2}\right), 39.7$ (Leu- $\beta-$ 
CH), 53.7 (Leu- $\alpha-C H), 68.3$ (C-5'), 69.1 (C-3'), 73.2 (C-2'), 81.3 (C-4'), 88.7 (C-1'), 102.2(C-5), 141.2 (C-6), 151.3 (C-2), 165.8 (C-4), 175.1 (C=O, Leu). HRMS [ESI] m/z: calcd. for $\mathrm{C}_{15} \mathrm{H}_{24} \mathrm{~N}_{4} \mathrm{O}_{9} \mathrm{~S}\left([\mathrm{M}]^{+}\right.$) 435.1191: found, 435.1184.

4.2.4.4. 5'-O-(N-L-leucyl)-sulfamoyl- $N^{3}$-methyluridine (6c)

The final compound was obtained in 65\% yield. ${ }^{1} \mathrm{HNMR}\left(300 \mathrm{MHz}, \mathrm{D}_{2} \mathrm{O}\right) \delta$ 0.93-0.98(m, 6H, Leu$\delta-\mathrm{CH}_{3}$ ), 1.66-1.81 (m, 3H, Leu- $\beta-\mathrm{CH}_{2}$ \& 1H-Leu- $\gamma-\mathrm{CH}$ ), 3.28 (s, 3H, N3-Me), 3.79-3.84 (m, $1 \mathrm{H}$, Leu- $\alpha-C H$ ), 4.28-4.50 (m, 5H, H-5'a, H-5'b, H-4' H-3', H-2'), 5.97 (d, 1H, J = 3.9Hz, H-1'), 6.12 (d, $1 \mathrm{H}, \mathrm{J}=7.6 \mathrm{~Hz}, \mathrm{H}-5), 7.85$ (d, 1H, $J=7.6 \mathrm{~Hz}, \mathrm{H}-6) .{ }^{13} \mathrm{C}$ NMR $\left(75 \mathrm{MHz}, \mathrm{D}_{2} \mathrm{O}\right) \delta 20.7\left(\mathrm{Leu}-\delta-\mathrm{CH}_{3}\right)$, $21.6\left(\mathrm{Leu}-\delta-\mathrm{CH}_{3}\right), 23.7\left(\mathrm{Leu}-\gamma-\mathrm{CH}_{2}\right), \delta 27.4$ (N3-Me), $39.9\left(\mathrm{Leu}-\beta-\mathrm{CH}_{2}\right), 53.9(\mathrm{Leu}-\alpha-\mathrm{CH}), 67.7$ (C5'), 69.0 (C-3'), 73.4(C-2'), 81.3 (C-4'), 89.6 (C-1'), 101.4 (C-5), 139.0 (C-6), 151.8 (C-2), 165.1 (C4), 176.0 (C=O, Leu). HRMS [ESI] m/z: calcd. for $\mathrm{C}_{16} \mathrm{H}_{25} \mathrm{~N}_{4} \mathrm{O}_{9} \mathrm{~S}$ ([M- H] $]^{-}$449.1348: found, 449.1352 .

4.2.4.5. 5'-O-(N-L-tyrosyl)-sulfamoyl-cytidine (7a).

For synthesis of $\mathrm{N}$-Boc-Tyr-OSu, DCC (1.3 equivalent) was added to a solution of Boc-Tyr-OH (1 equivalent) and $N$-hydroxysuccinimide (1.2 equivalent) in dry THF ( $3 \mathrm{~mL} / \mathrm{mmol})$ at $0{ }^{\circ} \mathrm{C}$. The mixture was stirred for $0.5 \mathrm{~h}$ at $0^{\circ} \mathrm{C}$, then for $2-6 \mathrm{~h}$ at room temperature under an argon atmosphere. The resulting dicyclohexylurea (DCU) was removed by filtration, and the filtrate was concentrated in vacuo to give the corresponding activated ester. This activated ester was used as such for coupling. The final compound was obtained in $30 \%$ yield. ${ }^{1} \mathrm{HNMR}\left(300 \mathrm{MHz}, \mathrm{D}_{2} \mathrm{O}\right) \delta 2.89(\mathrm{~d}, 2 \mathrm{H}, J=6.7 \mathrm{~Hz}$, Tyr- $\beta-\mathrm{CH}_{2}$ ), 3.56 (t, 1H, Tyr- $\alpha-\mathrm{CH}$ ), 4.18-4.26 (m, 5H, H-5'a, H-5'b, H-4' H-3', H-2'), 5.94-5.99 (m, 2H, H-5 and H-1'), 6.76 (d, 2H, $J=8.6 \mathrm{~Hz}$, Tyr-Ar-H) and 7.11 (d, 2H, $J=8.3 \mathrm{~Hz}$, Tyr-Ar-H), 7.74 (d, $1 \mathrm{H}, J=7.6 \mathrm{~Hz}, \mathrm{H}-6) .{ }^{13} \mathrm{C}$ NMR $\left(75 \mathrm{MHz}, \mathrm{D}_{2} \mathrm{O}\right) 39.0\left(\mathrm{Tyr}-\beta-\mathrm{CH}_{2}\right), 57.8$ (Tyr- $\left.\alpha-\mathrm{CH}\right), 67.1$ (C-5'), 68.9 (C-3'), 73.8 (C-2'), 81.0 (C-4'), 89.3 (C-1'), 96.1 (C-5), 115.4 (Tyr-ortho-C), 127.9 (Tyripso-C), 130.4 (Tyr-meta-C), 140.8 (C-6), 157.3 (C-2), 155.2 (Tyr-para-C), 165.8 (C-4), 181.9 (C=O, Tyr). HRMS [ESI] m/z: calcd. for $\mathrm{C}_{19} \mathrm{H}_{22} \mathrm{~N}_{5} \mathrm{O}_{9} \mathrm{~S}$ ([M-H] $\left.]^{-}\right)$484.1145: found, 484.1144.

4.2.4.6. 5'-O-( $N$-L- tyrosyl)-sulfamoyl-uridine (7b).

The final compound was obtained in 62\% yield. ${ }^{1} \mathrm{HNMR}\left(300 \mathrm{MHz}, \mathrm{D}_{2} \mathrm{O}\right) \delta 3.16(\mathrm{~d}, 2 \mathrm{H}, J=6.5 \mathrm{~Hz}$, Tyr- $\beta-\mathrm{CH}_{2}$ ), 4.02-4.06 (m, 1H, Tyr- $\alpha-\mathrm{CH}$ ), 4.21-4.36 (m, 5H, H-5'a, H-5'b, H-4' H-3', H-2'), 5.83 (d, 1H, $J=8.1 \mathrm{~Hz}, \mathrm{H}-5), 5.93$ (d, 1H, $J=4.5 \mathrm{~Hz}, \mathrm{H}-1$ '), 6.84 (d, 2H, $J=8.4 \mathrm{~Hz}$, Tyr-Ar-H) and 7.16 (d, 2H, $J=8.4 \mathrm{~Hz}$, Tyr-Ar-H), 7.72 (d, $1 \mathrm{H}, J=8.1 \mathrm{~Hz}, \mathrm{H}-6) .{ }^{13} \mathrm{C}$ NMR $\left(75 \mathrm{MHz}, \mathrm{D}_{2} \mathrm{O}\right) \delta 35.5$ (Tyr$\beta-\mathrm{CH}_{2}$ ), 56.2 (Tyr- $\left.\alpha-\mathrm{CH}\right), 67.9$ (C-5'), 69.1 (C-3'), 73.3 (C-2'), 81.3 (C-4'), 88.7 (C-1'), 102.1 (C-5), 
115.4 (Tyr-ortho-C), 125.6 (Tyr-ipso-C), 130.6 (Tyr-meta-C), 141.1 (C-6), 151.3 (C-2), 154.7 (Tyrpara-C), 165.8 (C-4), 172.2 (C=O, Tyr). HRMS [ESI] m/z: calcd. for $\mathrm{C}_{18} \mathrm{H}_{22} \mathrm{~N}_{4} \mathrm{O}_{10} \mathrm{~S}\left([\mathrm{M}-\mathrm{H}]^{-}\right)$ 485.0984: found, 485.0979.

4.2.4.7. 5'-O-(N-L- tyrosyl)-sulfamoyl- $N^{3}$-methyluridine (7c).

The final compound was obtained in $60 \%$ yield. ${ }^{1} \mathrm{HNMR}\left(300 \mathrm{MHz}, \mathrm{D}_{2} \mathrm{O}\right) \delta 3.15(\mathrm{~d}, 2 \mathrm{H}, J=3.1 \mathrm{~Hz}$, Tyr- $\beta-\mathrm{CH}_{2}$ ), 3.25 (s, 3H, N3-Me), 4.03 (m, 1H, Tyr- $\alpha-\mathrm{CH}$ ), 4.18-4.35 (m, 5H, H-5'a, H-5'b, H-4' H-3', H-2'), 5.86 (d, 1H, $J=8.1 \mathrm{~Hz}, \mathrm{H}-5$ ), 5.93 (d, 1H, $J=4.0 \mathrm{~Hz}, \mathrm{H}-1$ '), 6.80 (d, 2H, $J=8.5 \mathrm{~Hz}$, Tyr-Ar-H) and 7.13 (d, 2H, $J=8.5 \mathrm{~Hz}$, Tyr-Ar-H), 7.70 (d, $1 \mathrm{H}, J=8.1 \mathrm{~Hz}, \mathrm{H}-6) .{ }^{13} \mathrm{C}$ NMR $(75 \mathrm{MHz}$, $\left.\mathrm{D}_{2} \mathrm{O}\right) \delta 27.4$ (N3-Me), 35.5 (Tyr- $\beta-\mathrm{CH}_{2}$ ), 56.2 (Tyr- $\left.\alpha-\mathrm{CH}\right), 67.7$ (C-5'), 68.8 (C-3'), $73.40(\mathrm{C}-2$ '), 81.1 (C-4'), 89.8 (C-1'), 101.3 (C-5), 115.3 (Tyr-ortho-C), 125.5 (Tyr-ipso-C), 130.6 (Tyr-meta-C), 138.9 (C-6), 151.6 (C-2), 154.7 (Tyr-para-C), 165.0 (C-4), 174.2 (C=O, Tyr). HRMS [ESI] m/z: calcd. for $\mathrm{C}_{19} \mathrm{H}_{23} \mathrm{~N}_{4} \mathrm{O}_{10} \mathrm{~S}\left([\mathrm{M}-\mathrm{H}]^{-}\right)$499.1140: found, 499.1132.

\subsection{Inhibition assays with $E$. coli aaRS and with $\mathrm{S} 30$ whole cell extracts}

Cloning, expression and purification of E.coli aminoacyl-tRNA synthetases and purification of tRNA was performed as reported[28] (see supplementary file).

\subsubsection{In vitro inhibitory activity determination with purified $E$. coli aaRS}

To examine the inhibitory effect of the various compounds we performed a radiolabel transfer assay using purified E. coli aaRS. Briefly, either $10 \mathrm{nM}$ ileRS, $0.5 \mathrm{nM}$ tyrRS, $2.5 \mathrm{nM}$ leuRS, in $20 \mathrm{mM}$ Tris, $100 \mathrm{mM} \mathrm{KCl}, 10 \mathrm{mM} \mathrm{MgCl} 2,5 \mathrm{mM} \beta$-mercaptoethanol, $\mathrm{pH} 7.5$ was preincubated with the compound, at different concentrations, at $37^{\circ} \mathrm{C}$ in the presence of $50 \mu \mathrm{M}$ of the appropriate $14 \mathrm{C}$ labeled amino acid, $2 \mathrm{mg} / \mathrm{mL}$ tRNA and $0.5 \mathrm{mg} / \mathrm{mL}$ inorganic pyrophosphatase. After $10 \mathrm{~min}$, prewarmed ATP was added to the mixture at a final concentration of $500 \mu \mathrm{M}$. The reaction was quenched by addition of $0.2 \mathrm{M}$ sodium acetate $\mathrm{pH} 4,0.1 \% \mathrm{~N}$-lauroylsarcosine and $5 \mathrm{mM}$ unlabeled amino acid (2 mM for tyrosine). $20 \mathrm{~mL}$ was spotted on 3MM Whatman paper. After thorough washing with cold $10 \%$ TCA, the filters were washed twice with acetone and air dried. Addition of scintillation liquid was followed by measurement of the radio activity using scintillation counter. The linear zone of enzyme activity was determined for each aaRS. The quench time was picked within this zone at which approximately $50 \%$ of total RNA is aminoacylated. The quench time was 4, 6 and 8 minutes for leuRS, ileRS and tyrRS respectively. Copeland pointed out that when the $\mathrm{K}_{\mathrm{i}}{ }^{\mathrm{app}}$ of the compound approaches or is lower than the used enzyme concentration the Michaelis-Menten equation is no longer valid[27]. 
Therefore, the apparent inhibition constant $\left(\mathrm{K}_{\mathrm{i}}^{\text {app }}\right.$ or $\left.\mathrm{K}_{\mathrm{i}}{ }^{*}\right)$ is determined using the Greco-Hakala equation where $\mathrm{v}_{\mathrm{o}}$ is the rate of reaction in the absence of inhibitor, $\mathrm{v}_{\mathrm{i}}$ is the rate of reaction in the presence of inhibitor, $E_{o}$ is the concentration of enzyme and $I_{o}$ is the concentration of the inhibitor.

$$
v_{\mathrm{i}}=v_{0} \frac{E_{0}-I_{0}-K_{\mathrm{i}}^{*}+\sqrt{\left(E_{0}-I_{0}-K_{\mathrm{i}}^{*}\right)^{2}+4 E_{0} K_{\mathrm{i}}^{*}}}{2 E_{0}}
$$

\subsubsection{Preparation of normal S30 cell extract}

$10 \mu \mathrm{l}$ E. coli NCIB / E. coli wt (strain K-12 BW28357) / E. coli BL21 glycerol stock was used to inoculate $5 \mathrm{~mL}$ of LB-medium, and it was shaken overnight at $180 \mathrm{rpm}$ at $37^{\circ} \mathrm{C}$. Next morning 100 $\mu \mathrm{l}$ of this preculture was used to inoculate $180 \mathrm{~mL} \mathrm{LB}$ medium and the culture was grown until the optical density (at $600 \mathrm{~nm}$ ) reached $1.2 \mathrm{OD}$, usually in 4 hours. Cells were then transferred to four 50 $\mathrm{mL}$ falcon tube and centrifuged at $15,000 \mathrm{rpm}$ for $15 \mathrm{~min}$ at $4^{\circ} \mathrm{C}$, and the supernatant was decanted. The cell pellet was resuspended in $50 \mathrm{~mL}$ buffer containing $20 \mathrm{mM}$ Tris $\cdot \mathrm{HCl}, 10 \mathrm{mM} \mathrm{MgCl}$, 100 $\mathrm{mM} \mathrm{KCl}, \mathrm{pH}$ 8.0. The cell suspension was centrifuged again at $15,000 \mathrm{rpm}$ for $15 \mathrm{~min}$ at $4^{\circ} \mathrm{C}$. This procedure was repeated twice. The pellet was then resuspended in $1 \mathrm{~mL}$ of the same buffer, and $5 \mu \mathrm{L}$ of $1 \mathrm{M}$ DTT was added and kept at $0{ }^{\circ} \mathrm{C}$. Subsequently, the cells were sonicated for $30 \mathrm{~s}$ (at $80 \%$ amplitude, 0.5 cycle) and cooled on ice bath for 10 seconds; and this process is repeated 15 times. The lysate was centrifuged (17,000 rpm) at $4{ }^{\circ} \mathrm{C}$ for 15 min using a bench-top centrifuge and supernatant was taken and again centrifuged $(17,000 \mathrm{rpm})$ at $4{ }^{\circ} \mathrm{C}$ for $15 \mathrm{~min}$. The supernatant obtained was used as S30 cell extract.

\subsubsection{S30 cell extract for aminoacylation assay}

For the tRNA aminoacylation, a $20 \mu \mathrm{l}$ reaction was prepared. First, $1 \mu \mathrm{l}$ of the inhibitor (at a stock concentration of $5 \mu \mathrm{M}$ ) or buffer was added to $3 \mu$ of the E. coli S30 cell extract (10 times diluted with buffer) and incubated for $5 \mathrm{~min}$. Next, $16 \mu \mathrm{l}$ of the aminoacylation mixture which was kept at $37^{\circ} \mathrm{C}$ was added and which contains Tris. $\mathrm{HCl}$ (30 mM, pH 8.0), DTT (1 mM), E. coli MRE 600 tRNA (5 g/L purchased from Sigma), ATP (3 mM), KCl (30 mM), $\mathrm{MgCl}_{2}(8 \mathrm{mM})$, and the corresponding ${ }^{14} \mathrm{C}$-radiolabeled amino acid $(15 \mu \mathrm{M}, 28.59 \mu \mathrm{M}$, and $9.66 \mu \mathrm{M}$ for isoleucine, leucine and tyrosine respectively). The aminoacylation reaction was carried out at $37^{\circ} \mathrm{C}$. The reaction was quenched after 1 minute by addition of $0.2 \mathrm{M}$ sodium acetate $\mathrm{pH} 4,0.1 \% \mathrm{~N}$-lauroylsarcosine and $5 \mathrm{mM}$ unlabeled amino acid ( $2 \mathrm{mM}$ for tyrosine). Then $10 \mu \mathrm{L}$ of the reaction mixture was spotted on 3MM Whatman paper, and it was transferred to $10 \%$ cold TCA solution. The papers were washed thoroughly with 10\% cold TCA (twice), then the papers were washed twice with acetone and later dried in air. Dried papers were transferred to scintillation vial followed by the addition of scintillation liquid (12 mL), 
the amount of radionuclide incorporation was determined using a Tri-card 2300 TR liquid scintillation counter. The linear zone of enzyme activity present in the S30 extract was determined for each aaRS (see Supplementary Fig. S8). The quench time point was picked within this zone and with approximately $50 \%$ of total RNA aminoacylation.

\subsubsection{Prolonged incubation of compound with S30 cell extract to check the stability of the compounds}

For the stability testing of compounds, we used mixture of inhibitor (at a stock concentration of 5 $\mu \mathrm{M}$ ): S30 extract (1:3) or the mixture of inhibitor (at a stock concentration of $5 \mu \mathrm{M}$ ): acetyl-CoA (at stock concentration of $10 \mathrm{mM}$ ): S30 extract (1:1:3) which is incubated at $37^{\circ} \mathrm{C}$ for specific period of time. At the specified time intervals $4 \mu \mathrm{l}$ (or $5 \mu \mathrm{l}$ in case of acetyl-CoA mixture) of this inhibitorcellular extract mixture was taken and added to the $16 \mu \mathrm{l}$ (or $15 \mu \mathrm{l}$ in case of acetyl-CoA mixture) of the aminoacylation mixture which was kept at $37^{\circ} \mathrm{C}$ which contains Tris.HCl (30 mM, pH 8.0), DTT (1 mM), E. coli MRE 600 tRNA (5 g/L purchased from Sigma), ATP (3 mM), KCl (30 mM), $\mathrm{MgCl}_{2}$ (8 mM), and the corresponding ${ }^{14} \mathrm{C}$-radiolabeled amino acid $(10 \mu \mathrm{M}, 28.59 \mu \mathrm{M}$, and $9.66 \mu \mathrm{M}$ for isoleucine, leucine and tyrosine respectively). This reaction was quenched after 1-minute by addition of $0.2 \mathrm{M}$ sodium acetate $\mathrm{pH} 4,0.1 \% \mathrm{~N}$-lauroylsarcosine and $5 \mathrm{mM}$ cold isoleucine. And later steps were similar as described in section 4.3.3.

\subsubsection{Preparation of $\mathrm{S} 30$ cell extracts comprising overexpressed NATs}

The coding sequences for RimI, RimL and YhhY were amplified from E. coli BL21 (DE3) genomic DNA and cloned into pETCH vector[50] between the Nco I and Hind III restriction sites. The SUMO protein was already available in the pETSUK vector, and in-house vector derived from pETHSUL[50]. Plasmids were transformed into BL21 (DE3) pLysS E. coli cells and grown in $2 \mathrm{~L}$ $\mathrm{LB}$ at $37^{\circ} \mathrm{C}$ until OD 0.6, at which $0.1 \mathrm{mM}$ IPTG was added. The cultures overexpressing RimL and SUMO were incubated for another 3 hours at $37^{\circ} \mathrm{C}$ before harvesting. To increase the solubility of RimI and YhhY, the cultures were incubated for 24 hours at $18{ }^{\circ} \mathrm{C}$. Cells were harvested and resuspended into $50 \mathrm{mM}$ phosphate $\mathrm{pH}$ 7.5, $100 \mathrm{mM}$ potassium acetate and $10 \mathrm{mM}$ magnesium acetate and stored at $-80{ }^{\circ} \mathrm{C}$ until further workup. Cells were thawed and sonicated three times with a 30 mins incubation on ice between cycles. The lysate was clarified by centrifugation at $20000 \mathrm{~g}$ at 4 ${ }^{\circ} \mathrm{C}$ for 60 mins. The supernatant was carefully removed, aliquots were flash frozen in liquid nitrogen and stored at $-80^{\circ} \mathrm{C}$ until used.

\subsubsection{NAT activity determination using NAT overexpressed S30 cell extract}

To determine NAT activity, a mixture of inhibitor (at a stock concentration of $5 \mu \mathrm{M}$ ), acetyl-CoA (at a stock concentration of $1.25 \mathrm{mM})$, and respective S30 extract $(1: 1: 3)$ is incubated at $37^{\circ} \mathrm{C}$ for the 
specified period. The addition of inhibitor and acetyl-CoA mixture to cellular extract is done at timepoint zero and after 5 and 60 mins, respectively, $5 \mu \mathrm{l}$ of this mixture is added to $15 \mu \mathrm{l}$ of the aminoacylation mixture which was kept at $37^{\circ} \mathrm{C}$ and which contains phosphate (50 mM, pH 7.5), DTT (1 mM), E. coli MRE 600 tRNA (5 g/L purchased from Sigma), ATP (3 mM), magnesium acetate $(10 \mathrm{mM})$, potassium acetate $(100 \mathrm{mM})$, and the corresponding $14 \mathrm{C}$-radiolabeled amino acid (15 $\mu \mathrm{M}, 28.59 \mu \mathrm{M}$, and $9.66 \mu \mathrm{M}$ for isoleucine, leucine and tyrosine respectively). The aminoacylation reaction is quenched after 1-minute by addition of $0.2 \mathrm{M}$ sodium acetate $\mathrm{pH} 4,0.1 \%$ $\mathrm{N}$-lauroylsarcosine and $5 \mathrm{mM}$ unlabeled amino acid (2 $\mathrm{mM}$ for tyrosine). All following steps are as described in section 4.3.3.

\subsection{Crystallization}

Prior to crystallization, E. coli tyrRS was incubated in the presence of $10 \mathrm{mM}$ pyrophosphate on ice for 1 hour to remove the contaminating reaction intermediate. This was followed by buffer exchange into $10 \mathrm{mM}$ BIS-TRIS pH 6.5, $500 \mathrm{mM} \mathrm{KCl,} \mathrm{5 \%} \mathrm{v/v} \mathrm{ethylene} \mathrm{glycol} \mathrm{and} 2 \mathrm{mM}$ DTT using a Superdex 200 10/300 GL column (GE Healthcare Lifesciences). E. coli tyrRS crystals were grown using the hanging drop vapor diffusion technique at $20^{\circ} \mathrm{C}$ by mixing $2 \mu \mathrm{L}$ protein solution concentrated to 10 $\mathrm{mg} / \mathrm{ml}, 1.5 \mu \mathrm{L}$ of crystallization solution consisting out of 10-15\% PEG 3350, $20 \mathrm{mM}$ glutamate $\mathrm{pH}$ 6, $10 \mathrm{mM}$ BIS-TRIS pH 6.5 and 20\% v/v ethylene glycol and a $0.5 \mu \mathrm{L}$ seed stock. Crystals were transferred to a soaking solution containing 15\% w/v PEG-3350, $20 \mathrm{mM}$ glutamate pH 6, $10 \mathrm{mM}$ BIS-TRIS pH 6.5, 20\% ethylene glycol and $2 \mathrm{mM}$ compound and left for 5 hours before harvesting in a cryo-loop and flash freezing in liquid nitrogen.

$N$. gonorrhoeae leuRS was buffer exchanged into $10 \mathrm{mM}$ Tris $\mathrm{pH}$ 7, $100 \mathrm{mM} \mathrm{NaCl}, 2.5 \mathrm{mM} \beta$ mercaptoethanol using a Superdex 200 10/300 GL column and concentrated to $10 \mathrm{mg} / \mathrm{mL}$ with a centrifugal concentrator device. Final crystals were grown using the hanging-drop vapor-diffusion method from a 0.75:1.0:0.25 (v/v) mixture of protein and reservoir buffer containing 20\% w/v PEG 3350, $100 \mathrm{mM}$ bis-tris propane $\mathrm{pH} 8.5$ and $100 \mathrm{mM} \mathrm{MgCl}_{2}$ with the addition of crystal seeds from earlier optimizations in similar conditions. Suitable crystals were soaked with the corresponding ligand diluted in an equivalent precipitant solution supplemented with $22 \% \mathrm{v} / \mathrm{v}$ ethylene glycol for 2 hours. These crystals were subsequently mounted in cryo-loops and flash-cooled in liquid nitrogen prior to data collection.

Datasets were collected at synchrotron ESRF (Grenoble, France) or synchrotron Soleil (Paris, France). All datasets were processed using XDS[51], pointless[52], aimless[53] and ccp4[54], within 
the automated processing pipeline of autoproc[55]. E. coli tyrRS structures were solved using a molecular replacement with Phaser[56] using the previously published E. coli tyrRS structure (PDB: 4OUD) as a search model[57]. The model was optimized by iterative rounds of manual model building using Coot[58] and refined using BUSTER[59]. In the case of $N$. gonorrhoeae leuRS, initial phases were determined using molecular replacement employing a model generated from E. coli leuRS (PDB: 3ZJU)[60]. The initial solution was optimized by iterative rounds of manual model building in Coot[58] and refinement using Phenix[61]. All ligand restraints were generated by GRADE Web server. Enzyme-ligand interactions were analyzed using Schrödinger Maestro Software.

All compound-bound structures have been deposited to PDB under accession codes 6Q89, 6Q8A, 6Q8C, 6Q8B, 6I5Y, 6HB5, 6HB6, 6HB7 and full reports were obtained.

\section{Funding}

This work was supported by the Research Foundation Flanders [Fonds voor Wetenschappelijk Onderzoek, grants $\underline{\text { G077814N }}$ to S.V.S. and A.V.A., G0A4616N to S.D.W. and A.V.A., $\underline{12 A 3916 N}$ to B.G., G077814N to M.N. 1S53516N to S. D. G.], the KU Leuven Research Fund [grant 3M14022 to S.D.W. and A.V.A.]; and the Chinese Scholarship Council to L.P.

\section{Conflicts of interest}

No conflicts of interest are declared.

\section{Acknowledgements}

The authors thank the Belgian FWO for providing a SB Fellowship of the Research Foundation Flanders to Steff De Graef, the China Scholarship Council for providing scholarships to Luping Pang and KU Leuven for financial support. Mass spectrometry was made possible by the support of the Hercules Foundation of the Flemish Government [20100225E7]. We further greatly appreciate the support from the beamline scientists at the PROXIMA 1 and PROXIMA 2A (Soleil Synchrotron, France) and ID23-1, ID30A3 and ID29 (ESRF, France) beamlines in facilitating the collection of Xray scattering data. We are also indebted to Luc Baudemprez for help with NMR spectra measurement and Jef Rozenski for providing MS analysis.

\section{REFERENCES}


[1] G.H.M. Vondenhoff, A. Van Aerschot, Aminoacyl-tRNA synthetase inhibitors as potential antibiotics, Eur. J. Med. Chem., 46 (2011) 5227-5236.

[2] G. Raczniak, M. Ibba, D. Soll, Genomics-based identification of targets in pathogenic bacteria for potential therapeutic and diagnostic use, Toxicol, 160 (2001) 181-189.

[3] J.G. Hurdle, A.J. O'Neill, I. Chopra, Prospects for Aminoacyl-tRNA Synthetase Inhibitors as New Antimicrobial Agents, Antimicrob. Agents Chemother., 49 (2005) 4821-4833.

[4] B. Gadakh, A. Van Aerschot, Aminoacyl-tRNA synthetase inhibitors as antimicrobial agents: a patent review from 2006 till present, Expert. Opin. Ther. Pat., 22 (2012) 1453-1465.

[5] J.S. Tao, P. Schimmel, Inhibitors of aminoacyl-tRNA synthetases as novel anti-infectives, Expert opinion on investigational drugs, 9 (2000) 1767-1775.

[6] R.V.K. Cochrane, A.K. Norquay, J.C. Vederas, Natural products and their derivatives as tRNA synthetase inhibitors and antimicrobial agents, Medchemcomm, 7 (2016) 1535-1545.

[7] P. Fang, M. Guo, Evolutionary limitation and opportunities for developing tRNA synthetase inhibitors with 5-binding-mode classification, Life, 5 (2015) 1703-1725.

[8] B. Gadakh, S. Smaers, J. Rozenski, M. Froeyen, A. Van Aerschot, 5 '-(N-aminoacyl)-sulfonamido5 '-deoxyadenosine: Attempts for a stable alternative for aminoacyl-sulfamoyl adenosines as aaRS inhibitors, Eur. J. Med. Chem., 93 (2015) 227-236.

[9] M. Serpi, V. Ferrari, F. Pertusati, Nucleoside Derived Antibiotics to Fight Microbial Drug Resistance: New Utilities for an Established Class of Drugs?, J. Med. Chem., 59 (2016) 1034310382.

[10] M.J.B. Brown, L.M. Mensah, M.L. Doyle, N.J.P. Broom, N. Osbourne, A.K. Forrest, C.M. Richardson, P.J. O'Hanlon, A.J. Pope, Rational design of femtomolar inhibitors of isoleucyl tRNA synthetase from a binding model for pseudomonic acid-A, Biochemistry, 39 (2000) 6003-6011.

[11] B.P. Duckworth, T.W. Geders, D. Tiwari, H.I. Boshoff, P.A. Sibbald, C.E. Barry, 3rd, D. Schnappinger, B.C. Finzel, C.C. Aldrich, Bisubstrate adenylation inhibitors of biotin protein ligase from Mycobacterium tuberculosis, Chem. Biol., 18 (2011) 1432-1441.

[12] M.R. Bockman, C.A. Engelhart, S. Dawadi, P. Larson, D. Tiwari, D.M. Ferguson, D. Schnappinger, C.C. Aldrich, Avoiding Antibiotic Inactivation in Mycobacterium tuberculosis by Rv3406 through Strategic Nucleoside Modification, Acs Infectious Diseases, 4 (2018) 1102-1113.

[13] T. Kazakov, K. Kuznedelov, E. Semenova, D. Mukhamedyarov, K.A. Datsenko, A. Metlitskaya, G.H. Vondenhoff, A. Tikhonov, V. Agarwal, S. Nair, A. Van Aerschot, K. Severinov, The RimL Transacetylase Provides Resistance to Translation Inhibitor Microcin C, J. Bacteriol., 196 (2014) 3377-3385.

[14] M. Serpi, V. Ferrari, F. Pertusati, Nucleoside Derived Antibiotics to Fight Microbial Drug Resistance: New Utilities for an Established Class of Drugs?, Journal of Medicinal Chemistry, 59 (2016) 10343-10382.

[15] M.H. Charlton, R. Aleksis, A. Saint-Leger, A. Gupta, E. Loza, L.R. de Pouplana, I. Kaula, D. Gustina, M. Madre, D. Lola, K. Jaudzems, G. Edmund, C.P. Randall, L. Kime, A.J. O'Neill, W. Goessens, A. Jirgensons, P.W. Finn, N-Leucinyl Benzenesulfonamides as Structurally Simplified Leucyl-tRNA Synthetase Inhibitors, ACS Med. Chem. Lett., 9 (2018) 84-88.

[16] B. Gadakh, G. Vondenhoff, E. Lescrinier, J. Rozenski, M. Froeyen, A. Van Aerschot, Base substituted 5 '-O-( $\mathrm{N}$-isoleucyl)sulfamoyl nucleoside analogues as potential antibacterial agents, Bioorg. Med. Chem., 22 (2014) 2875-2886.

[17] G.H. Vondenhoff, B. Gadakh, K. Severinov, A. Van Aerschot, Microcin C and albomycin analogues with aryl-tetrazole substituents as nucleobase isosters are selective inhibitors of bacterial aminoacyl tRNA synthetases but lack efficient uptake, ChemBioChem, 13 (2012) 19591969. 
[18] X.Y. Yu, J.M. Hill, G.X. Yu, W.H. Wang, A.F. Kluge, P. Wendler, P. Gallant, Synthesis and structure-activity relationships of a series of novel thiazoles as inhibitors of aminoacyl-tRNA synthetases, Bioorganic \& Medicinal Chemistry Letters, 9 (1999) 375-380.

[19] P. Schimmel, J.S. Tao, J. Hill, Aminoacyl tRNA synthetases as targets for new anti-infectives, FASEB J., 12 (1998) 1599-1609.

[20] X.Y. Yu, J.M. Hill, G. Yu, Y. Yang, A.F. Kluge, D. Keith, J. Finn, P. Gallant, J. Silverman, Structureactivity relationship of biphenylquinoline analogs as inhibitors of $S$. aureus methionyl-tRNA synthetase, Abstracts of Papers American Chemical Society, 218 (1999) 296-MEDI 296.

[21] V. Agarwal, G. Vondenhoff, B. Gadakh, K. Severinov, A. Van Aerschot, S.K. Nair, Exploring the substrate promiscuity of an antibiotic inactivating enzyme, Medchemcomm, 5 (2014) 1567-1570.

[22] M. Novikova, T. Kazakov, G.H. Vondenhoff, E. Semenova, J. Rozenski, A. Metlytskaya, I.

Zukher, A. Tikhonov, A. Van Aerschot, K. Severinov, MccE Provides Resistance to Protein Synthesis Inhibitor Microcin C by Acetylating the Processed Form of the Antibiotic, Journal of Biological Chemistry, 285 (2010) 12662-12669.

[23] M. Serebryakova, Tsibulskaya, D., Mokina, O., Kulikovsky, A., Nautiyal, M., Van Aerschot, A., Severinov, K. and Dubiley, S., A Trojan-Horse Peptide-Carboxymethyl-Cytidine Antibiotic fromBacillus amyloliquefaciens, J. Am. Chem. Soc., 138 (2016) 15690-15698.

[24] D. Tsibulskaya, O. Mokina, A. Kulikovsky, J. Piskunova, K. Severinov, M. Serebryakova, S. Dubiley, The Product of Yersinia pseudotuberculosis mcc Operon Is a Peptide-Cytidine Antibiotic Activated Inside Producing Cells by the TIdD/E Protease, Journal of the American Chemical Society, 139 (2017) 16178-16187.

[25] H.D. Flosadottir, H. Jonsson, S.T. Sigurdsson, O. Ingolfsson, Experimental and theoretical study of the metastable decay of negatively charged nucleosides in the gas phase, Phys. Chem. Chem. Phys., 13 (2011) 15283-15290.

[26] M.D. Erion, K.R. Reddy, S.H. Boyer, M.C. Matelich, J. Gornez-Galeno, R.H. Lemus, B.G. Ugarkar, T.J. Colby, J. Schanzer, P.D. van Poelje, Design, synthesis, and characterization of a series of cytochrome P-450 3A-activated prodrugs (HepDirect prodrugs) useful for targeting phosph(on)atebased drugs to the liver, J. Am. Chem. Soc., 126 (2004) 5154-5163.

[27] R.A. Copeland, Evaluation of Enzyme Inhibitors in Drug Discovery: A Guide for Medicinal Chemists and Pharmacologists, 2nd Edition, Evaluation of Enzyme Inhibitors in Drug Discovery: a Guide for Medicinal Chemists and Pharmacologists, 2nd Edition, (2013) 245-285.

[28] B. Zhang, S. De Graef, M. Nautiyal, L. Pang, B. Gadakh, M. Froeyen, L. Van Mellaert, S.V. Strelkov, S.D. Weeks, A. Van Aerschot, Family-wide analysis of aminoacyl-sulfamoyl-3deazaadenosine analogues as inhibitors of aminoacyl-tRNA synthetases, Eur. J. Med. Chem., 148 (2018) 384-396.

[29] K. Severinov, S.K. Nair, Microcin C: biosynthesis and mechanisms of bacterial resistance, Future Microbiology, 7 (2012) 281-289.

[30] A. Schmidt, K. Kochanowski, S. Vedelaar, E. Ahrne, B. Volkmer, L. Callipo, K. Knoops, M. Bauer, R. Aebersold, M. Heinemann, The quantitative and condition-dependent Escherichia coli proteome, Nat. Biotechnol., 34 (2016) 104-110.

[31] T. Nakama, O. Nureki, S. Yokoyama, Structural basis for the recognition of isoleucyl-adenylate and an antibiotic, mupirocin, by isoleucyl-tRNA synthetase, Journal of Biological Chemistry, 276 (2001) 47387-47393.

[32] J.J. Perona, A. Hadd, Structural Diversity and Protein Engineering of the Aminoacyl-tRNA Synthetases, Biochemistry, 51 (2012) 8705-8729. 
[33] T. Kobayashi, T. Takimura, R. Sekine, K. Vincent, K. Kamata, K. Sakamoto, S. Nishimura, S. Yokoyama, Structural snapshots of the KMSKS loop rearrangement for amino acid activation by bacterial tyrosyl-tRNA synthetase, J. Mol. Biol., 346 (2005) 105-117.

[34] T. Kobayashi, K. Sakamoto, T. Takimura, R. Sekine, V.P. Kelly, K. Kamata, S. Nishimura, S. Yokoyama, Structural basis of nonnatural amino acid recognition by an engineered aminoacyltRNA synthetase for genetic code expansion (vol 102, pg 1366, 2005), Proc. Natl. Acad. Sci. U. S. A., 102 (2005) 10405-10405.

[35] A. Palencia, T. Crepin, M.T. Vu, T.L. Lincecum, Jr., S.A. Martinis, S. Cusack, Structural dynamics of the aminoacylation and proofreading functional cycle of bacterial leucyl-tRNA synthetase, Nat.

Struct. Mol. Biol., 19 (2012) 677-684.

[36] S. Doublie, G. Bricogne, C. Gilmore, C.W. Carter, Tryptophanyl-transfer-RNA synthetase crystal-struture reveals an unexpected homology to tyrosyl-transfer-RNA synthethase, Structure, 3 (1995) 17-31.

[37] L.D. Sherlin, J.J. Perona, tRNA-dependent active site assembly in a class I aminoacyl-tRNA synthetase, Structure, 11 (2003) 591-603.

[38] S. Sekine, O. Nureki, D.Y. Dubois, S. Bernier, R. Chenevert, J. Lapointe, D.G. Vassylyev, S. Yokoyama, ATP binding by glutamyl-tRNA synthetase is switched to the productive mode by tRNA binding, Embo Journal, 22 (2003) 676-688.

[39] B. Delagoutte, D. Moras, J. Cavarelli, tRNA aminoacylation by arginyl-tRNA synthetase: induced conformations during substrates binding, Embo Journal, 19 (2000) 5599-5610.

[40] V.L. Rath, L.F. Silvian, B. Beijer, B.S. Sproat, T.A. Steitz, How glutaminyl-tRNA synthetase selects glutamine, Structure, 6 (1998) 439-449.

[41] D.Y. Dubois, C. Habegger-Polomat, L.-P. Gagnon, J. Lapointe, R. Chênevert, Glutamylsulfamoyladenosine and pyroglutamylsulfamoyladenosine are competitive inhibitors of $\mathrm{E}$. coli glutamyl-tRNA synthetase AU - Bernier, Stéphane, J. Enzyme Inhib. Med. Chem., 20 (2005) 6168.

[42] A.K. Forrest, R.L. Jarvest, L.M. Mensah, P.J. O'Hanlon, A.J. Pope, R.J. Sheppard, Aminoalkyl adenylate and aminoacyl sulfamate intermediate analogues differing greatly in affinity for their cognate Staphylococcus aureus aminoacyl tRNA synthetases, Bioorg. Med. Chem. Lett., 10 (2000) 1871-1874.

[43] M. Desjardins, S. Garneau, J. Desgagnes, L. Lacoste, F. Yang, J. Lapointe, R. Chenevert, Glutamyl adenylate analogues are inhibitors of glutamyl-tRNA synthetase, Bioorg. Chem., 26 (1998) 1-13.

[44] G.D. Wright, Bacterial resistance to antibiotics: Enzymatic degradation and modification, Adv. Drug Deliv. Rev., 57 (2005) 1451-1470.

[45] A. Tikhonov, T. Kazakov, E. Semenova, M. Serebryakova, G. Vondenhoff, A. Van Aerschot, J.S. Reader, V.M. Govorun, K. Severinov, The mechanism of microcin C resistance provided by the MccF peptidase, J. Biol. Chem., 285 (2010) 37944-37952.

[46] M.N. Alekshun, S.B. Levy, Molecular mechanisms of antibacterial multidrug resistance, Cell, 128 (2007) 1037-1050.

[47] V. Agarwal, A. Metlitskaya, K. Severinov, S.K. Nair, Structural Basis for Microcin C7 Inactivation by the MccE Acetyltransferase, J. Biol. Chem., 286 (2011) 21295-21303.

[48] L. Lain, H. Lonnberg, T. Lonnberg, Intramolecular Participation of Amino Groups in the Cleavage and Isomerization of Ribonucleoside 3 '-Phosphodiesters: The Role in Stabilization of the Phosphorane Intermediate, Chem. Eur. J., 19 (2013) 12424-12434.

[49] Y. Hisamatsu, K. Hasada, F. Amano, Y. Tsubota, Y. Wasada-Tsutsui, N. Shirai, S.-i. Ikeda, K. Odashima, Highly selective recognition of adenine nucleobases by synthetic hosts with a linked 
five-six-five-membered triheteroaromatic structure and the application to potentiometric sensing of the adenine nucleotide, Chem. Eur. J., 12 (2006) 7733-7741.

[50] S.D. Weeks, M. Drinker, P.J. Loll, Ligation independent cloning vectors for expression of SUMO fusions, Protein Expr. Purif., 53 (2007) 40-50.

[51] W. Kabsch, XDS, Acta Crystallogr. Sect. D. Biol. Crystallogr., 66 (2010) 125-132.

[52] P. Evans, Scaling and assessment of data quality, Acta Crystallogr. Sect. D. Biol. Crystallogr., 62 (2006) 72-82.

[53] P.R. Evans, G.N. Murshudov, How good are my data and what is the resolution?, Acta Crystallogr. Sect. D. Biol. Crystallogr., 69 (2013) 1204-1214.

[54] M.D. Winn, C.C. Ballard, K.D. Cowtan, E.J. Dodson, P. Emsley, P.R. Evans, R.M. Keegan, E.B. Krissinel, A.G.W. Leslie, A. McCoy, S.J. McNicholas, G.N. Murshudov, N.S. Pannu, E.A. Potterton, H.R. Powell, R.J. Read, A. Vagin, K.S. Wilson, Overview of the CCP4 suite and current developments, Acta Crystallogr. Sect. D. Biol. Crystallogr., 67 (2011) 235-242.

[55] C. Vonrhein, C. Flensburg, P. Keller, A. Sharff, O. Smart, W. Paciorek, T. Womack, G. Bricogne, Data processing and analysis with the autoPROC toolbox, Acta Crystallogr. Sect. D. Biol. Crystallogr., 67 (2011) 293-302.

[56] A.J. McCoy, R.W. Grosse-Kunstleve, P.D. Adams, M.D. Winn, L.C. Storoni, R.J. Read, Phaser crystallographic software, J. Appl. Crystallogr., 40 (2007) 658-674.

[57] D.J. Mandell, M.J. Lajoie, M.T. Mee, R. Takeuchi, G. Kuznetsov, J.E. Norville, C.J. Gregg, B.L. Stoddard, G.M. Church, Biocontainment of genetically modified organisms by synthetic protein design, Nature, 518 (2015) 55-60.

[58] P. Emsley, B. Lohkamp, W.G. Scott, K. Cowtan, Features and development of Coot, Acta Crystallogr. Sect. D. Biol. Crystallogr., 66 (2010) 486-501.

[59] G. Bricogne, E. Blanc, M. Brandl, C. Flensburg, P. Keller, W. Paciorek, P. Roversi, A. Sharff, O.S. Smart, C. Vonrhein, T.O. Womack, BUSTER version 2.10.3., in, Global Phasing Ltd., Cambridge, United

Kingdom, 2017.

[60] V. Hernandez, T. Crepin, A. Palencia, S. Cusack, T. Akama, S.J. Baker, W. Bu, L. Feng, Y.R. Freund, L. Liu, M. Meewan, M. Mohan, W. Mao, F.L. Rock, H. Sexton, A. Sheoran, Y. Zhang, Y.K. Zhang, Y. Zhou, J.A. Nieman, M.R. Anugula, M. Keramane el, K. Savariraj, D.S. Reddy, R. Sharma, R. Subedi, R. Singh, A. O'Leary, N.L. Simon, P.L. De Marsh, S. Mushtaq, M. Warner, D.M. Livermore, M.R. Alley, J.J. Plattner, Discovery of a novel class of boron-based antibacterials with activity against gram-negative bacteria, Antimicrob Agents Chemother, 57 (2013) 1394-1403.

[61] P.D. Adams, P.V. Afonine, G. Bunkoczi, V.B. Chen, I.W. Davis, N. Echols, J.J. Headd, L.-W. Hung, G.J. Kapral, R.W. Grosse-Kunstleve, A.J. McCoy, N.W. Moriarty, R. Oeffner, R.J. Read, D.C. Richardson, J.S. Richardson, T.C. Terwilliger, P.H. Zwart, PHENIX: a comprehensive Python-based system for macromolecular structure solution, Acta Crystallogr. Sect. D. Biol. Crystallogr., 66 (2010) 213-221. 